\section{RECEIVED \\ AUG 141997 \\ OSTI}

oAK RIDGE

NATIONAL

LABORATORY

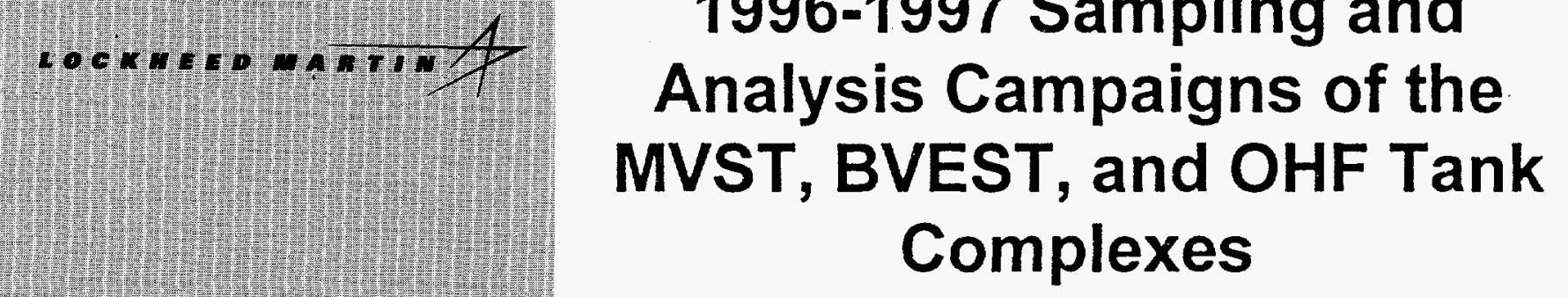

\section{Miscellaneous Data for the 1996-1997 Sampling and Analysis Campaigns of the Complexes}

\author{
J. M. Giaquinto \\ J. M. Keller \\ T.P. Mills
}

MMAGEO AWD OPERMTED BY

LOCKHEEO UARM ENERGY RESEARCH CORPORATION FORTHE UWTED STATES

DEPARIVET Or EVERGY

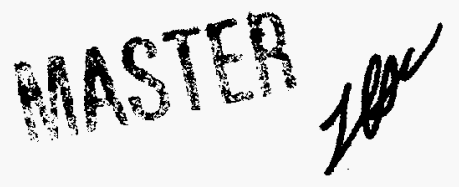


This report has been reproduced directly from the best available copy.

Available to DOE and DOE contractors from the Office of Scientific and Technical Information, P. O. Box 62, Oak Ridge, TN 37831; prices available from (423) 576-8401, FTS 626-8401.

Available to the public from the National Technical Information Service, U.S. Department of Commerce, 5285 Port Royal Road, Springfield, VA 22161.

This report was prepared as an account of work sponsored by an agency of the United States Government. Neither the United States Government nor any agency thereof, nor any of their employees, makes any warranty, express or implied, or assumes any legal liability or responsibility for the accuracy, completeness, or usefulness of any information, apparatus, product, or process disclosed, or represents that its use would not infringe privately owned rights. Reference herein to any specific commercial product, process, or service by trade name, trademark, manufacturer, or otherwise, does not necessarily constitute or imply its endorsement, recommendation, or favoring by the United States Government or any agency thereof. The views and opinions of authors expressed herein do not necessarily state or reflect those of the United States Government of any agency thereof. 


\section{DISCLAIMER}

Portions of this document may be illegible in electronic image products. Images are produced from the best available original document. 


\title{
Miscellaneous Data for the 1996-1997 Sampling and Analysis Campaigns of the MVST, BVEST, and OHF Tank Complexes
}

\author{
J. M. Giaquinto \\ J. M. Keller \\ T.P. Mills*
}

*Kelly Scientific Resources, Oak Ridge, TN 37830

July 1997

\author{
Prepared by the \\ OAK RIDGE NATIONAL LABORATORY \\ Oak Ridge, Tennessee 37831 \\ managed by \\ LOCKHEED MARTIN ENERGY RESEARCH CORP. \\ for the \\ U.S. DEPARTMENT OF ENERGY \\ under contract \\ DE-AC05-96OR22464
}




\section{TABLE OF CONTENTS}

LIST OF TABLES $\ldots \ldots \ldots \ldots \ldots \ldots \ldots \ldots \ldots \ldots \ldots \ldots \ldots \ldots \ldots \ldots \ldots \ldots \ldots \ldots$ iii

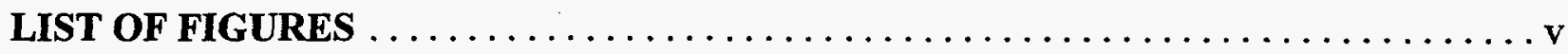

ACKNOWLEDGMENTS $\ldots \ldots \ldots \ldots \ldots \ldots \ldots \ldots \ldots \ldots \ldots \ldots \ldots \ldots \ldots \ldots$ vii

ABBREVIATIONS AND ACRONYMS $\ldots \ldots \ldots \ldots \ldots \ldots \ldots \ldots \ldots \ldots$ ix

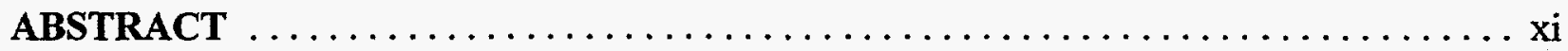

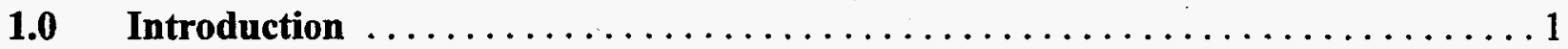

2.0 Total Anion Content in the Sludges $\ldots \ldots \ldots \ldots \ldots \ldots \ldots \ldots \ldots \ldots \ldots \ldots$

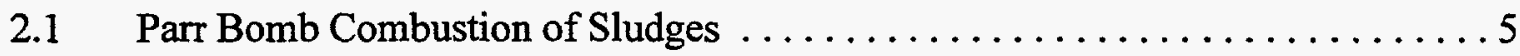

2.2 Nitric Acid Microwave Digestion of Sludges for Total Phosphate $\ldots \ldots \ldots 66$

2.3 Sodium Hydroxide/Peroxide Fusions of Sludges $\ldots \ldots \ldots \ldots \ldots \ldots \ldots$

2.4 Total Anion Content in the Sludges $\ldots \ldots \ldots \ldots \ldots \ldots \ldots \ldots$

2.5 Discussion of Total Anion Results in Sludges .................. 11

2.5.1 Halides (fluoride, chloride, bromide) $\ldots \ldots \ldots \ldots \ldots \ldots \ldots \ldots \ldots$

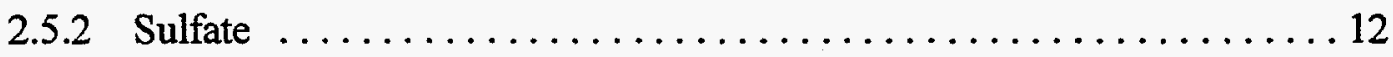

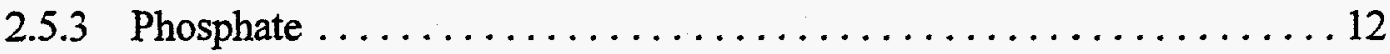

3.0 Settling Tests for the OHF and BVEST Tanks $\ldots \ldots \ldots \ldots \ldots \ldots \ldots \ldots \ldots \ldots$

4.0 Dry Density Measurements on MVST Sludges $\ldots \ldots \ldots \ldots \ldots \ldots \ldots \ldots \ldots$

5.0 Particle Size Analysis of Selected Sludges $\ldots \ldots \ldots \ldots \ldots \ldots \ldots \ldots \ldots \ldots \ldots$

$5.1 \quad$ Discussion of Instrument Theory $\ldots \ldots \ldots \ldots \ldots \ldots \ldots \ldots \ldots \ldots \ldots \ldots \ldots \ldots$

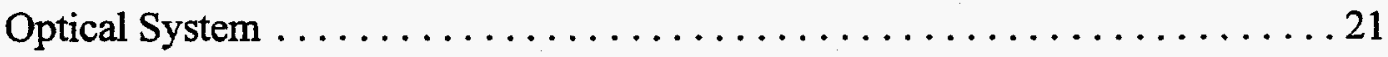

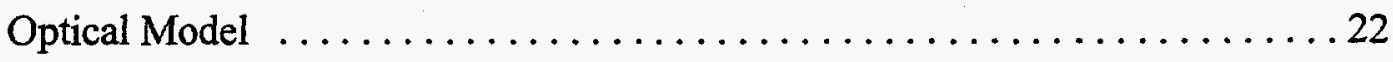




\section{TABLE OF CONTENTS (continued)}

5.2 Discussion of Result Interpretation and Reporting Conventions . . . . . . 23

6.0 Analysis of Selected MVST Supernants for Hydroxylamines . . . . . . . . . . . 29

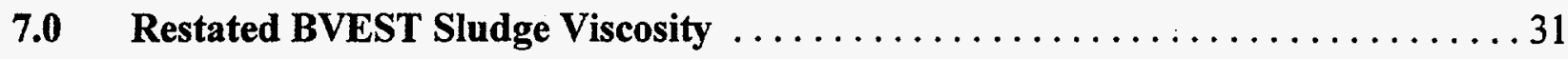

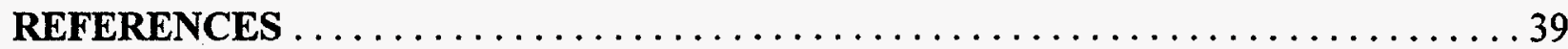

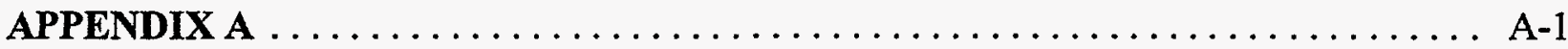




\section{LIST OF TABLES}

Table

2.4.1

3.1

4.1

5.1

6.1
Summary of Total Anion Data 10

OHF and BVEST Physical Data 17

BVEST and MVST Dried Densities 20

Distribution Modal Sizes $(\mu \mathrm{m})$ 24

T-4 Sludge Derived Diameters and Modal Size $(\mu \mathrm{m})$ 25

W-21 Sludge Derived Diameters and Modal Size $(\mu \mathrm{m})$ 26

W-22 Sludge Derived Diameters and Modal Size $(\mu \mathrm{m})$ 27 Hydroxylamine Content of Selected MVST Supernants 29 


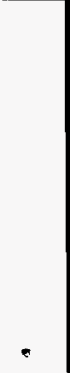




\section{LIST OF FIGURES}

Figure

\section{1}

3.2

3.4

5.1

5.2

5.3

7.1

7.2

7.3

7.4

7.5

7.6

7.7

7.8

7.9

7.10
OHF Settling Volumes

BVEST Settling Volumes

OHF Settling Rate (Relative)

BVEST Settling Rate (Relative)

Particle Size Characterization for T-4

Particle Size Characterization for W-21

Particle Size Characterization for W-22

Apparent Viscosity vs. Shear Rate for W-21 Sludge Composite 34

Shear Stress vs. Shear Rate for W-21 Sludge Composite 34 Apparent Viscosity vs. Shear Rate for W-22 Sludge Composite 35

Shear Stress vs. Shear Rate for W-22 Sludge Composite $\ldots \ldots \ldots \ldots \ldots 35$

Apparent Viscosity vs. Shear Rate for W-22 Sludge Composite (Duplicate) . . 36

Shear Stress vs. Shear Rate for W-22 Sludge Composite (Duplicate) . . . . . . 36

Apparent Viscosity vs. Shear Rate for W-22 Sludge Composite (Static) $\ldots . .37$

Shear Stress vs. Shear Rate for W-22 Sludge Composite (Static) 37

Apparent Viscosity vs. Shear Rate for W-23 Sludge Composite 38

Shear Stress vs. Shear Rate for W-23 Sludge Composite 38 


\section{ACKNOWLEDGMENTS}

The authors wish to express appreciation to the following staff members of the ORNL Chemical and Analytical Sciences Division who made important contributions to this work:

Inorganic and Radiochemical Analytical Support

L. D. Bible

R. D. Canaan

D. A. Caquelin

D. L. Denton

P. V. Ditavong

The authors also wish to express appreciation to the following staff members of the Liquid and Gaseous Waste Operation Department of the Office of Waste Management and Remedial Actions for tank sampling support:

Sampling Radioactive Waste Tanks

J. D. Brewer

C. B. Scott 


\section{ABBREVIATIONS AND ACRONYMS}

$\begin{array}{ll}\text { BVEST } & \text { Bethel Valley Evaporator Service Tanks } \\ \text { DOT } & \text { Department of Transportation } \\ \text { IC } & \text { Ion Chromatography } \\ \text { ICP-AES } & \text { Inductively Coupled Plasma - Atomic Emission Spectroscopy } \\ \text { ICP-MS } & \text { Inductively Coupled Plasma - Mass Spectrometry } \\ \text { GFAA } & \text { Graphite Furnace Atomic Absorption } \\ \text { LCS } & \text { Laboratory Control Sample } \\ \text { LLLW } & \text { Liquid Low-Level Waste } \\ \text { MVST } & \text { Melton Valley Storage Tanks } \\ \text { NTS } & \text { Nevada Test Site } \\ \text { OHF } & \text { Old Hydrofracture Facility } \\ \text { PA } & \text { Performance Assessment } \\ \text { QC } & \text { Quality Control } \\ \text { RMAL } & \text { Radioactive Materials Analytical Laboratory (Building 2026) } \\ \text { RPD } & \text { Relative Percent Difference } \\ \text { TBP } & \text { Tributyl phosphate } \\ \text { WAG } & \text { Waste Area Grouping } \\ \text { WAC } & \text { Waste Acceptance Criteria } \\ \text { WIPP } & \text { Waste Isolation Pilot Project } \\ \text { XRD } & \text { X-ray Diffraction } \\ \text { XRF } & \end{array}$




\section{ABSTRACT}

Starting in 1996 and continuing into 1997, there were several major sampling and analysis campaigns undertaken to characterize the contents of the Active Liquid Low-Level Waste (LLLW) tanks located at ORNL and the Old Hydrofracture Facility (OHF) tanks located in Melton Valley within Waste Area Grouping (WAG) 5. The active LLLW tanks include the Melton Valley Storage Tanks (MVST) and the Bethel Valley Evaporator Service Tanks (BVEST). The characterization data obtained for these campaigns are summarized in three earlier ORNL technical reports. Included in these reports are data which addresses waste processing options, performance assessment (PA) for the Waste Isolation Pilot Plant (WIPP), criticality concerns, and DOT requirements for transporting the waste. Also, included is an evaluation of the waste's characteristics with respect to the waste acceptance criteria (WAC) for WIPP and Nevada Test Site (NTS).

As part of these campaigns there were also other miscellaneous tests performed and data collected to address important engineering and remediation issues that were not included in the previous reports. These miscellaneous tests are summarized in this report and include 1) fusion preparations for total anion analysis on selected MVST, BVEST, and OHF sludges, 2) settling tests performed on the BVEST and OHF sludges, 3) dried density data for the MVST sludges, 4) particle size analysis on selected BVEST and OHF sludges, and 5) the analysis of hydroxylamine in the BVEST supernates and sludges. Also, the viscosity and flow curves for BVEST waste are restated in this report using apparent viscosity with further detail included about the flow characteristics that were observed. 


\title{
Miscellaneous Data for the 1996-1997 Sampling and Analysis Campaigns of the MVST, BVEST, and OHF Tank Complexes
}

\author{
J. M. Giaquinto, J. M. Keller, T.P. Mills
}

\subsection{Introduction}

Starting in 1996 and continuing through 1997, a major sampling and analytical effort was undertaken to characterize the contents of the Melton Valley Storage Tanks (MVST), Bethel Valley Evaporator Storage Tanks (BVEST), and the Old Hydrofracture Facility (OHF) tanks. Three previously published ORNL reports ${ }^{1-3}$ provide comprehensive data and information which addresses waste processing options, performance assessment (PA) for the Waste Isolation Pilot Plant (WIPP), criticality concerns, and Department of Transportation (DOT) requirements for transporting the waste. Also included in these reports is an evaluation of the wastes characteristics with respect to the waste acceptance criteria (WAC) for WIPP and Nevada Test Site (NTS). There were, however, a number of other issues and concerns that were not included in these earlier reports. This report summarizes these miscellaneous tests and experiments.

For remediation efforts knowledge of the total anion content of the sludge is important. A typical procedure used to prepare soils and sludges for anion analysis, and the one that was used to report anion content in the previous reports, is simply to perform a water leach of the material and analyze the leachate. This preparation procedure, although quick and cost effective, only provides data on the anions which are present as water soluble compounds. Presented in this report is anion data which was determined using a peroxide/hydroxide fusion preparation of the sludges. The data, which is presented in section 2.0 , provides a more complete picture of the anion content in the sludges.

Settling data was needed for engineering design to determine the rate at which suspended sludges would settling out of a slurried mixture of sludge and supernatant. This data should provide insight into what would take place inside a closed piping system in which the slurried mixture was being 
transported in case the mode of force was halted. A crude settling rate test was performed on the BVEST and OHF sludges and the data is summarized in section 3.0.

Dried density data was requested to be performed for the MVST sludges. This data is listed in section 4.0.

Particle size distributions of the sludges are important for pump design. A particle size analysis was performed on selected sludges from the BVEST and OHF complexes using a light scattering based particle size analyzer. This data is presented in section 5.0.

Due to the recent concerns about the hazards associated with hydroxylamines, it was decided to analyze selected tanks for their presence. Selected MVST supernatants were analyzed using ion chromatography and the data is summarized in section 6.0.

In section 7.0 the BVEST viscosity and flow curves are restated in this report using apparent viscosity vs true viscosity and further detail is provided about the flow characteristics observed. 


\subsection{Total Anion Content in the Sludges}

Due to the complex precipitation chemistry of the waste tank sludges, the measurements of total anion content is difficult. The conventional preparation method used to determine anions in soils and sludges is a simple water leach of the sample. For previous reports the primary sludge anion data was based on such a water leach in which a 1 gram aliquot of wet sludge was added to a total volume of $10 \mathrm{ml}$ of water and mixed for 10 minutes. The leachate was then analyzed for the common inorganic anions using ion chromatography (IC), and the results were corrected back to the weight of the wet sludge. This method although quick and simple, will only yield accurate results for those anions which are present as water soluble compounds. Insoluble compounds will not be included. From past observations, the nitrate content usually dominates both the anionic mass and charge concentration in the sludges, and the nitrate compounds present in the waste tanks readily dissolve in water and should be accounted for in the water leaches. Based on this, it is believed that the water leaches are accounting for the majority of the anion concentration in the wastes. For waste stabilization processes, however, an accurate determination of the total anion concentration, with emphasis on total phosphorous as phosphate and total sulfur as sulfate, is needed. As an example, tributyl phosphate (TBP), which is commonly used as an extractant for nuclear processing, is believed to make-up a large fraction of the phosphorous in the sludges. Tributyl phosphate exhibits low solubility in water and would not be seen in the water leaches. In high temperature waste stabilization processes however, the tributyl phosphate could interfere with the process. A total phosphorous as phosphate could give an indication of the TBP present in the sludge. The reported sulfate concentrations, although typically seen in the water leaches, can not be called a total concentration due to the fact that there is the possibility of sulfate compounds being present in the sludges which have low solubility in water.

The Radioactive Materials Analytical Laboratory (RMAL) has studied a number of procedures to be used for total anion analysis of the waste tank sludges. A brief summary of each is given below. It is important to note that these procedures will yield a total concentration of the element measured and should not be considered as a total "anion" concentration but instead be interpreted to be a total elemental concentration. The analysis of total sulfate can be used as an example. A water leach of the sludge will yield a sulfate concentration due to water soluble compounds containing sulfate while 
an aggressive oxidizing preparation procedure, such as the ones described in this report, of the sludge would yield a sulfate concentration due not only to the compounds containing sulfates (both water soluble and insoluble) but any compound containing the element sulfur. In other words these procedures yield a total sulfur concentration, reported as sulfate, rather than a total sulfate anion concentration in the sludge. In theory, the same principle applies to any anion determined using these preparation methods.

Lastly, it is difficult to compare the yield for nitrate and nitrite anions between a water leach and an oxidizing preparation method. For these preparation methods the sample is subject to an oxidizing environment which will not only change the nitrate/nitrite ratio in the sample but will also oxidize any other nitrogen containing compounds present in the sample to nitrate or nitrite. The ratio of the nitrate/nitrite measured after preparation does not represent the ratio in the original sample and will not be reported here. 


\subsection{Parr Bomb Combustion of Sludges}

The bomb combustion preparations were performed using a model 1108 stainless steel bomb manufactured by Parr instrument company (211 Fifty-Third Street, Moline, IL. 61265). This preparation method involves combusting the sludge in an oxygen rich environment with the use of a combustion aid. The procedure used for the bomb combustion is outlined below.

1. Approximately $0.25 \mathrm{~g}$ of sludge was weighed into the combustion crucible.

2. One-half $\mathrm{mL}$ of mineral oil was added to the crucible with the sample.

3. One $\mathrm{mL}$ of $1 \underline{\mathrm{M}}$ sodium hydroxide was placed on the bottom of the bomb.

4. The bomb was assembled, charged to $30 \mathrm{~atm}$. with UHP (ultra-high purity) oxygen, and vented. This flush was repeated two more times to remove nitrogen. The bomb was charged to a final pressure of $30 \mathrm{~atm}$ with UHP oxygen, placed into a water bath and then the sample was ignited with an electronic spark.

5. The bomb was allowed to stand in the water bath for $4 \mathrm{~min}$. to condense combustion gases.

6. The bomb condensate was rinsed three times into a flask and diluted to $50 \mathrm{~mL}$ with water.

The resulting solution was analyzed by ion chromatography for anions.

This preparation method was used on the BVEST sludges with little success. To obtain an adequate combustion of a material undergoing bomb combustion, 5000 calories of heat must be produced in the bomb. The waste tank sludges do not contain appreciable quantities of combustible material and the heat must be generated by the combustion aid (mineral oil). A material that undergoes complete combustion should have an ash like appearance. Visual observation of the sludge after combustion 
showed that the sludge appears to be just dried out with a crusty appearance. The results of the bomb combustion are reported in reference 2. Although the halides (fluoride, chloride, and bromide) results compared with results from the water leach, there was very little phosphate detected and there was poor agreement between the water leach and bomb combustion for sulfate (generally the bomb results were lower). Based on these results and the observations described above, it is believed that the sludge did not undergo decomposition but had only been dried by the bomb process. The procedure basically resulted in a water leach of the dried sludge. The RMAL determined that the bomb was a poor choice for preparation of waste tank sludges for total anion determinations.

\subsection{Nitric Acid Microwave Digestion of Sludges for Total Phosphate}

Using this preparation method, a small aliquot of the sludge is digested with $10 \mathrm{ml}$ of concentrated nitric acid in a sealed teflon vessel. The protocol followed was SW-846 Method 3051, Microwave Assisted Acid Digestion of Sediments, Sludges, Soils, and Oils in which the sludge/acid mixtures were raised to $175^{\circ} \mathrm{C}$ in $5.5 \mathrm{~min}$. and held at that temperature for 4.5 minutes. At the completion of the digestion, the samples were allowed to cool and then filtered to remove the solid residue. The filtrate was then diluted to $50 \mathrm{ml}$ with water. The diluted samples were analyzed for phosphorus and other metals using inductively coupled plasma atomic emission spectrometry (ICP-AES). The total phosphorus results were converted to phosphate by multiplying by a weight conversion factor (3.07). This procedure was initially used to obtain a quick confirmation of the fact that there were phosphate compounds present in the sludges which were not being detected using a basic water leach preparation.

Because the RMAL's ICP-AES employs fiber optics to transmit the emitted analytical wavelengths from the plasma to the optical system, the optimal emission line for phosphorus determination could not be used. This optimal emission line is in the ultraviolet portion of the wavelength spectrum which can not be transmitted through the fibers. Instead, an alternate emission line had to be chosen for the analysis. The alternate line is not only less sensitive to the optimal wavelength line but is also subject to extreme interferences from the other metals, particularly iron, in the samples. Although there were corrections applied to the data to account for the interferences they were not successful and typically the reported total phosphate results using ICP-AES were erroneously high. 
It is assumed that after digestion all phosphorous in the digested solution would be oxidized to it's highest oxidation state $(+5)$ and be present in solution as phosphate $\left(\mathrm{PO}_{4}^{-3}\right)$. Therefore, it should be possible to precipitate the interferences out of solution without the loss of phosphorus by making the preparations basic. There was some concern that phosphorus may also precipitate out of solution when the basic precipitations are performed but initial tests using MVST W-31 sludge comparing phosphorus results obtained on precipitated basic microwave preparations with the phosphate values obtained on fusion preparations show that phosphorus is staying in solution with no loss due to precipitation. The results are shown in table 2.4.1 and discussed in section 2.5.3.

Samples generated from the nitric acid microwave digestion can also be analyzed for total sulfate and phosphate by $\mathrm{IC}$ using an analytical column on which the retention times for these analytes are long enough that interference due to the resultant large nitrate peak is prevented. This method was used for total phosphate determination in the BVEST sludges due to loss of the phosphate during the fusion preparation, which is described below, and the problems associated with the ICP. More information is provided about this in section 2.5.3.

\subsection{Sodium Hydroxide/Peroxide Fusions of Sludges}

This preparation method involves oxidizing a small aliquot of sludge at high temperatures for $15 \mathrm{~min}$ in a caustic environment. Once the fusion melt has cooled but before solids form the fused material is rinsed into a volumetric flask and diluted to $50 \mathrm{ml}$ volume with type II water. The procedure used for the fusions is as follows.

1. Approximately $0.5 \mathrm{~g}$ of sludge was weighed into a nickel crucible.

2. Reagent grade sodium peroxide $(1.5 \mathrm{~g})$ and ultra pure sodium hydroxide $(1.0 \mathrm{~g})$ was added to the crucible with the sample.

3. The crucible with the sample and reagents was covered and placed in a muffle furnace set at $600^{\circ} \mathrm{C}$ for $15 \mathrm{~min}$. 
4. The samples were removed from the furnace and allowed to cool for 3-4 min

5. The cover, crucible, and fusion salts were rinsed with water into a flask and diluted to $50 \mathrm{ml}$.

The final solution was analyzed for fluoride, chloride, bromide, phosphate, and sulfate using a Dionex (1228 Titan Way, Sunnyvale, CA. 94088) 4500i ion chromatograph and total phosphorus using a Spectro Analytical Instruments (160 Authority Drive, Fitchburg, MA. 01420) Spectroflame ICP-AES for comparison.

Initially, when this method was used, there were a number of problems noted that needed to be resolved before it could be considered to be viable. First, the resulting sample matrix created during the preparation is extremely caustic with high levels of sodium due to the reagents used. This caused severe interferences in the ion chromatograms which made it impossible to obtain results for the earlier eluting constituents such as fluoride and chloride. An additional problem noted was very poor phosphate and sulfate recoveries in the sample spikes and laboratory control samples (LCS). The poor recoveries indicated that the elements were being lost during the fusion process, and the results obtained on the samples could not be considered accurate. To resolve these matrix effects, a cation exchange resin was used to remove the bulk of the cation species (ie. sodium) and clean-up the matrix prior to injection into the IC. For this clean-up a Mini-Sep ${ }^{\mathrm{TM}}$ solid phase extraction cartridge obtained from Chrom Tech, Inc. (P.O. Box 24248, Apple Valley, MN. 55124) was used. These cartridges contain $500 \mathrm{mg}$ of cation exchange resin with a female luer lock inlet which easily fits onto the outlet of a plastic syringe. With these type cartridges, the sample can be pushed through using the syringe, and the liquid collected in a sample vial for analysis. The procedure used for sample clean-up is as follows.

1. The cation exchange resin is activated by passing $3 \mathrm{ml}$ of $1 \mathrm{M} \mathrm{HNO}_{3}$ over the resin.

2. The resin is rinsed with $3 \mathrm{ml}$ of type II water. 
3. A $5 \mathrm{ml}$ volume of a ten-fold dilution of the fusion preparation is passed over the resin and the liquid collected in an autosampler vial for analysis by IC.

Using the above clean-up procedure the matrix effects were sufficiently eliminated from the sample preparations to allow for accurate ion chromatography analysis. The samples were first diluted by a factor of ten prior to clean-up to prevent overloading the cation exchange resin. An undiluted clean-up would have been sufficient for the later eluting anions, but for the early eluting constituents (fluoride and chloride) there still would have been enough interfering species left, due to breakthrough, in the sample to prevent quantitation.

The second issue to be resolved was the loss of phosphate and sulfate during the fusion. It was surmised that these elements were being lost during the fusion due to reactions with the surface of the nickel crucibles. To prevent these reactions from occurring, the surface of the crucibles were passivated by heating in a muffle furnace set at $600^{\circ} \mathrm{C}$ for four hours. This heating step caused an

oxide layer to form on the crucibles surface which is passive to the sample and prevents any surface reactions from taking place. Using passivated nickel crucibles the recoveries of the phosphate and sulfate spikes and LCS have increased to greater than $75 \%$. As explained in the coming sections however there are other mechanisms which cause the loss of phosphorus which had to be resolved in order to obtain an accurate total phosphate analysis.

\subsection{Total Anion Content in the Sludges}

Using the above outlined fusion procedure with passivated nickel crucibles and the cation exchange clean-up step, all of the OHF south end tank sludges (reported in reference 3), BVEST sludges from W-21 and W-23 (reported in reference 2), and MVST W-31 sludge (reported in reference 1) were re-analyzed for total anions. Due to the loss of phosphate however during the fusion process, the BVEST sludges were prepared for total phosphate analysis using microwave digestion and analyzed by ion chromatography. This is discussed more in section 2.5.3. All results are summarized in table 2.4.1. The water leach results that were originally reported are also listed for comparison. Where applicable the total phosphate concentration obtained by ICP-AES is shown. It should be noted that 
the fusion aliquots analyzed by ICP-AES did not undergo a cation exchange clean-up step prior to analysis since the interferences noted on the ion chromatograph would not affect the ICP.

Table 2.4.1

Summary of Total Anion Data

\begin{tabular}{||l|l|l|c|c|c|c|c|c|c|c||}
\hline Anion & Preparation & & \multicolumn{7}{|c|}{ Results ${ }^{1}$ (mg/Kg) } \\
\cline { 4 - 12 } & Method & & T-1 & T-2 & T-3 & T-4 & T-9 & W-21 & W-23 & W-31 \\
& & & (south) & (south) & (south) & (south) & (south) & & & \\
\hline Bromide & Water Leach & IC & $<4.8$ & $<4.8$ & 19.7 & $<4.6$ & 26.1 & 96.8 & 362 & $<45$ \\
& Fusion & IC & $<45.8$ & $<45.7$ & $<37.7$ & $<49.8$ & $<50.5$ & $<85.5$ & 463 & 81.0 \\
\hline Chloride & Water Leach & IC & 296 & 494 & 1130 & 462 & 3240 & 1370 & 3420 & 2570 \\
& Fusion & IC & 593 & 756 & 1320 & 665 & 3420 & 2190 & 3510 & 3050 \\
\hline \multirow{2}{*}{ Fluoride } & Water Leach & IC & 117 & 161 & 207 & 133 & 87.8 & 23.3 & 149 & 125 \\
& Fusion & IC & 1270 & 1250 & 1090 & 1010 & 1510 & 653 & 623 & 1520 \\
\hline Phosphate & Water Leach & IC & $<9.6$ & $<9.7$ & $<10.0$ & $<9.3$ & $<8.7$ & $<10$ & $<10$ & $<45$ \\
& Fusion & IC & 2610 & 1060 & 3690 & 930 & 1940 & - & - & 5630 \\
& Fusion & ICP-AEs & 3080 & 973 & 4080 & 867 & 2690 & - & - & 6360 \\
& Microwave & IC & - & - & - & - & - & $10600^{2}$ & 12100 & - \\
& Microwave & ICP-AEs & - & - & - & - & - & - & - & $6170^{3}$ \\
\hline \multirow{3}{*}{ Sulfate } & Water Leach & IC & 365 & 908 & 3430 & 1360 & 503 & 6030 & 3850 & 1090 \\
& Fusion & IC & 747 & 1210 & 3860 & 1710 & 1230 & 16100 & 7960 & 2080 \\
\hline
\end{tabular}

1) Due to the sample preparation and complex matrices a $30 \%$ error is assigned for each result.

2) Result believed to be approximately $30 \%$ high due to loss of moisture in the archived sample. See section 2.5.3.

3) Digestate analyzed after a basic precipitation 


\subsection{Discussion of Total Anion Results in Sludges}

Based on our work, the sodium peroxide/sodium hydroxide fusion preparation appears to be the best preparation method for total anion analysis. The resulting solution is suitable for analysis of total anions by IC or total phosphorus by ICP-AES. The basic matrix precipitates a large portion of the interfering elements out of solution that hinder the analysis of total phosphorus by ICP and once the initial issues involving matrix problems on the IC and analyte losses were resolved, the method has proven to yield good results with control checks within acceptable quality control (QC) requirements. It is important to be aware of the possible loss of phosphorus during the fusion, evaluating each sample and determining if an alternate digestion method should be used. A number of matrix spikes and laboratory control samples were analyzed during the tests for bromide, chloride, fluoride, phosphate, and sulfate. With the exception of phosphate recovery for the BVEST matrix, spikes all were within the acceptable range of $75 \%-125 \%$ recovery. Also, a number of duplicates were analyzed with a relative percent difference (RPD) of less than $30 \%$ for each analyte. All raw data and QC data are on file at the RMAL.

\subsubsection{Halides (fluoride, chloride, bromide)}

In the earlier reports the total fluoride and chloride values could not be reported due to matrix effects. It was thought that a water leach should be adequate for a total halide result. The data presented here shows that this was not a valid assumption. For chloride, there is close agreement between the water leaches and the fusion preparations but overall the trend shows slightly higher chloride values are obtained with the fusion. For fluoride the fusion preparations yield values that are approximately a factor of ten higher than the water leaches. This illustrates the fact that a water leach of the sludges does not account for all of the fluoride present in the sample and that a majority of the fluoride is present in the sludges as water insoluble compounds. For bromide there was good agreement overall in that it was either not detected or was near the detection limit of the instrument after dilution. W23 was the exception. This sample had sufficient bromide present such that a good comparison could be made between the two preparation methods and even though the fusion value was slightly 
higher the RPD between the two is only $24 \%$. Based on this and the trend of low bromide in all of the preparations, it is believed for these tanks a water leach is sufficient for a total bromide analysis.

\subsubsection{Sulfate}

Generally the fusions yield sulfate concentrations that are a factor of two higher than those obtained using a water leach. Tanks T-3 and T-4 south end sludge samples however did have adequate agreement between the water leach and fusion preparations to conclude that the majority of the sulphate compounds in these sludges are soluble in water and are accounted for using a simple water leach.

\subsubsection{Phosphate}

As expected the fusion values for phosphate are significantly higher than those of the water leaches. As noted earlier a large fraction of the phosphate in the sludges is surmised to be from the oxidation of tributyl phosphate and degradation products dibutyl- and monobutyl phosphate and would not be seen in the water leaches. The fusion results do show that there is phosphorus containing compounds present in the sludges that are not being accounted for with the water leaches. It is important to note that during a caustic fusion when phosphorus in the sample is heated with liquid sodium hydroxide, phosphine $\left(\mathrm{PH}_{3}\right)$ may form ${ }^{4}$. Phosphine is extremely volatile and will be lost during the fusion preparation. The loss of phosphorus was monitored through the use of matrix spikes. This may be a poor monitor for phosphorus loss, however, since all spikes used were compounds of phosphate which may not react the same as other phosphorus containing compounds which may be present in the sludges. The OHF and MVST matrix spikes for phosphate were all recovered within the acceptance criteria and based on this it was assumed that all of the phosphorus in the sample was accounted for. The BVEST sludges however displayed poor recoveries ranging from $0 \%$ to $10 \%$. Also, no phosphate was detected in any of the fusion preparations for these sludges. Due to this loss of phosphorus the BVEST sludges were prepared for phosphorus analysis using microwave acid digestion. If a loss of phosphorus is expected during a caustic preparation, such as the fusion preparation used for this report, it is best to put the phosphorus into solution using a strong oxidizer 
such as $\mathrm{HNO}_{3}$. It would be prudent to conduct future studies comparing phosphate recoveries using fusion preparations and microwave acid digestions on all the OHF sludges and the other MVST sludges to determine if any phosphorus is being loss during the caustic fusion process. Each tank series is summarized below.

All OHF sludge fusion preparations were analyzed for $\mathrm{PO}_{4}$ content using both IC and ICP-AES. The results obtained from the two independent analysis methods are comparable. As stated earlier the fusions basic matrix precipitates a large portion of the interfering elements out of solution that hinder the analysis of total phosphorus by ICP making the analysis much easier.

Separate portions of MVST W-31 sludge were prepared using both the fusion and closed vessel microwave preparations to conduct a comparison study for total phosphorus analysis by ICP. Each preparation batch consisted of an original sample, matrix spike, matrix spike duplicate, laboratory control sample, and a preparation blank. The microwave preparations were made basic prior to analysis by ICP and the fusion preparations were analyzed by IC. The phosphate results obtained by ICP for the two digestion methods showed good precision with a RPD of $3 \%$. They also agree with the results obtained by IC. The relative percent standard deviation between the three values is $5 \%$.

This quick study does demonstrate that for the W-31 sludge there is no phosphorus loss in the fusion preparation and a comparable phosphate value can be obtained on the waste tank sludges with the current ICP configuration from the same microwave preparations that are used for other metals, once they are made basic, precluding the need for a separate fusion preparation for total phosphorus.

As mentioned earlier the fusion preparations phosphate spike recoveries for the BVEST sludges W21 and W-23 ranged from $0 \%$ to $10 \%$. Also, no phosphate was detected in the samples prepared by the fusion method but based on poor spike recoveries, it was believed that phosphorus was being lost during the fusion. To prevent the loss of phosphorus during the digestion process, microwave acid digestion was used to prepare the BVEST sludges for phosphate analysis. The digestates were analyzed by IC for phosphate and sulfate. Sulfate was analyzed so that a comparison could be made between the performance of acid digestion and the fusion preparation. All acid digested phosphate matrix spike recoveries and duplicate recoveries were within the acceptance criteria. The sulfate 
value obtained on the W-23 acid digestion compared well to the fusion results $(<20 \% \mathrm{RPD})$ but, the value obtained on the W-21 acid digestion was $30 \%$ higher than that obtained by fusion. The explanation for this is believed to be loss of moisture in that sample. The BVEST sludge samples were used for numerous fusion experiments to try to determine a solution for the loss of phosphorus. These experiments required a lot of sludge aliquots and by the time the last test was done (microwave digestion with IC analysis) the W-21 sludge supply was nearly depleted with the only inventory left on the container wall. Visually one could observe that the small portion of sludge remaining had lost some moisture and therefore it was assumed that this resulted in high phosphate and sulfate analysis on that sludge aliquot. 


\subsection{Settling Tests For The OHF and BVEST Tanks}

Settling characteristics are an important consideration in removal of the waste from the Bethel Valley and Hydrofracture tanks, since the undissolved solids content is a high percentage of the total slurry. The settling rate of undissolved solids in a solution is determined by the terminal velocities of the various particles. The terminal velocity can be calculated according to the following equation:

$$
\mathrm{V}_{s}=\mathrm{g} \mathrm{a}^{2}\left(\mathrm{~d}_{1}-\mathrm{d}_{2}\right) / 18 \mu \quad \text { (Stoke's Law) }
$$

where: $\mathrm{a}=$ the radius of the spherical particle

$d_{1}=$ the density of the sphere

$\mathrm{d}_{2}=$ the density of the medium

$\mu=$ fluid viscosity.

$\mathrm{g}=$ gravitational constant

Settling tests were conducted in a hot cell on portions of the OHF and BVEST sludge cores using the following simplified procedure:

1. From the already settled sample, the supernate layer was decanted leaving behind the wet sludge.

2. A portion of this sludge was introduced into a graduated cylinder ( $100 \mathrm{ml}$ capacity for the OHF, $250 \mathrm{ml}$ capacity for the BVST).

3. To the sludge, a portion of supernate from the same tank was added so the volumes were at approximately a 1:1 ratio in the graduated cylinder.

4. The cylinder was capped and inverted several times with the manipulator arms to suspend all solids.

5. A small portion of this suspension was poured off to determine the percent moisture of each slurry.

6. All cylinders were positioned upright to start the settling test. The first two hours of settling was continuously recorded with a camcorder. For the next two weeks following, recordings were taken at various intervals during the working day. 
7. At the end of the test period, the video record was used to plot the settling rate for each sample. Measurements were recorded in volume units according to the graduation of the cylinder at which the interface between the mostly sludge layer and the mostly liquid layer lie.

This method is a crude but effective substitute for predicting the net effect of what would happen should a pump break or flow of the slurry be in some way forced to stop during the removal/transfer process. There are some factors which may affect the settling data, such as visual restrictions and temperature changes, which need to be considered. The visual restrictions due to the hot cell zinc bromide window will affect the accuracy of the settling data. Visual observations of particles in a clear solution ceases at approximately 50 to 65 microns. Due to the approximately 4 feet of Zinc bromide solution (in the hot cell windows) between the observer and the samples, this visibility is decreased. Although the temperature fluctuated between 28 and 30 degrees Celcius in the cell it is considered to be a small enough change to not be a factor. It is also important to note that the graduated cylinders stood vertical during the entire time of the settling, since any angle introduced to the column would change (increase) the settling rate due to collection of the particles on the side of the column.

According to Stoke's law the largest particles will fall out of suspension the fastest, and of course the most dense particles will fall quicker than those which are less dense. This law assumes that first, the particles are spherical in shape, which will usually not be the case, and second, a solid particle would not allow flow of molecules and other particles through itself. In this experiment there is not enough information to apply Stoke's law to predict a settling curve. However, the application of Stoke's Law using the available data across the same times required in the settling tests produces distances of travel that are consistent with the physical setup of the experiment.

The results from the determination of the \% solids of the slurry mixtures are tabulated in table 3.1 and the settling results are shown in figures 3.1 through 3.4. 
Table 3.1

OHF and BVEST Physical Data

\begin{tabular}{|c|c|c|c|c|}
\hline Tank & pH & $\begin{array}{c}\text { Total Solids } \\
(\%) \\
\end{array}$ & $\begin{array}{l}\text { Suspended } \\
\text { Solids (\%) }\end{array}$ & $\begin{array}{c}\text { Constituents } \\
\text { over } 1 \% \\
\end{array}$ \\
\hline $\mathrm{T} 1$ & 9.0 & 16.2 & & $\begin{array}{c}\mathrm{Ca}, \mathrm{Fe}, \mathrm{Th}, \\
\text { TOC }\end{array}$ \\
\hline $\mathrm{T} 2$ & 9.3 & 12.6 & & $\begin{array}{c}\mathrm{Al}, \mathrm{Ca}, \mathrm{Fe} \\
\mathrm{Th}, \mathrm{TOC}\end{array}$ \\
\hline $\mathrm{T} 3$ & 11.2 & 19.8 & & $\begin{array}{c}\mathrm{Al}, \mathrm{Ca}, \mathrm{Na}, \\
\mathrm{Th}\end{array}$ \\
\hline $\mathrm{T} 4$ & 9.9 & 13.1 & & $\mathrm{Al}, \mathrm{Ca}, \mathrm{Th}$ \\
\hline T9 & 9.2 & 14.8 & & $\begin{array}{c}\mathrm{Ca}, \mathrm{Fe}, \mathrm{Th}, \\
\text { TOC }\end{array}$ \\
\hline W21 & 7.7 & 37.6 & 13.5 & $\begin{array}{c}\mathrm{Ca}, \mathrm{K}, \mathrm{Mg} \\
\mathrm{Na}, \mathrm{U}, \mathrm{TOC}\end{array}$ \\
\hline W22 & 11.3 & 21.4 & 19.5 & $\begin{array}{c}\mathrm{Ca}, \mathrm{Na}, \mathrm{U}, \\
\mathrm{TOC}\end{array}$ \\
\hline W23 & 12.3 & 42.3 & 17.3 & $\begin{array}{c}\mathrm{Ca}, \mathrm{K}, \mathrm{Mg}, \\
\mathrm{Na}, \mathrm{Th}\end{array}$ \\
\hline
\end{tabular}

Figures 3.1 and 3.2 show the absolute settling rate as the height of the settled/unsettled interface in milliliters (according to the graduations on the cylinder) versus the time in hours following shake up, first for the Hydrofracture, then for the BVEST tanks. The next set of graphs (Figs. 3.3 \& 3.4) are from the same data converted to percent solids left in suspension by subtracting the ratio of the current change in height to the final change in the interface height from 1. The graph results appear to have no direct correlation to either the bulk density or the calculated dry density of the respective sludges. 
Figure 3.1 OHF Settling Volumes

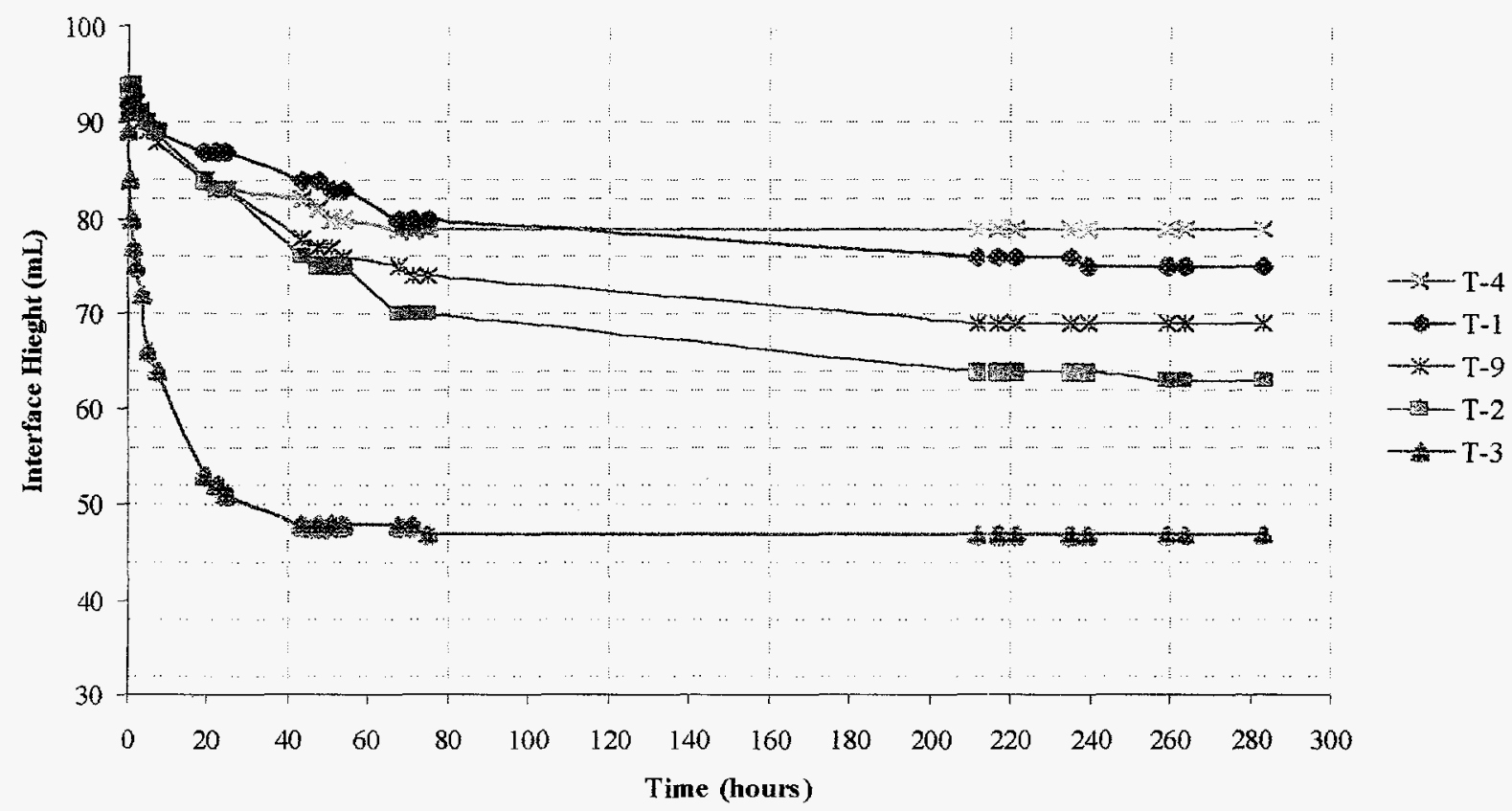

Figure 3.2 BVEST Settling Volumes

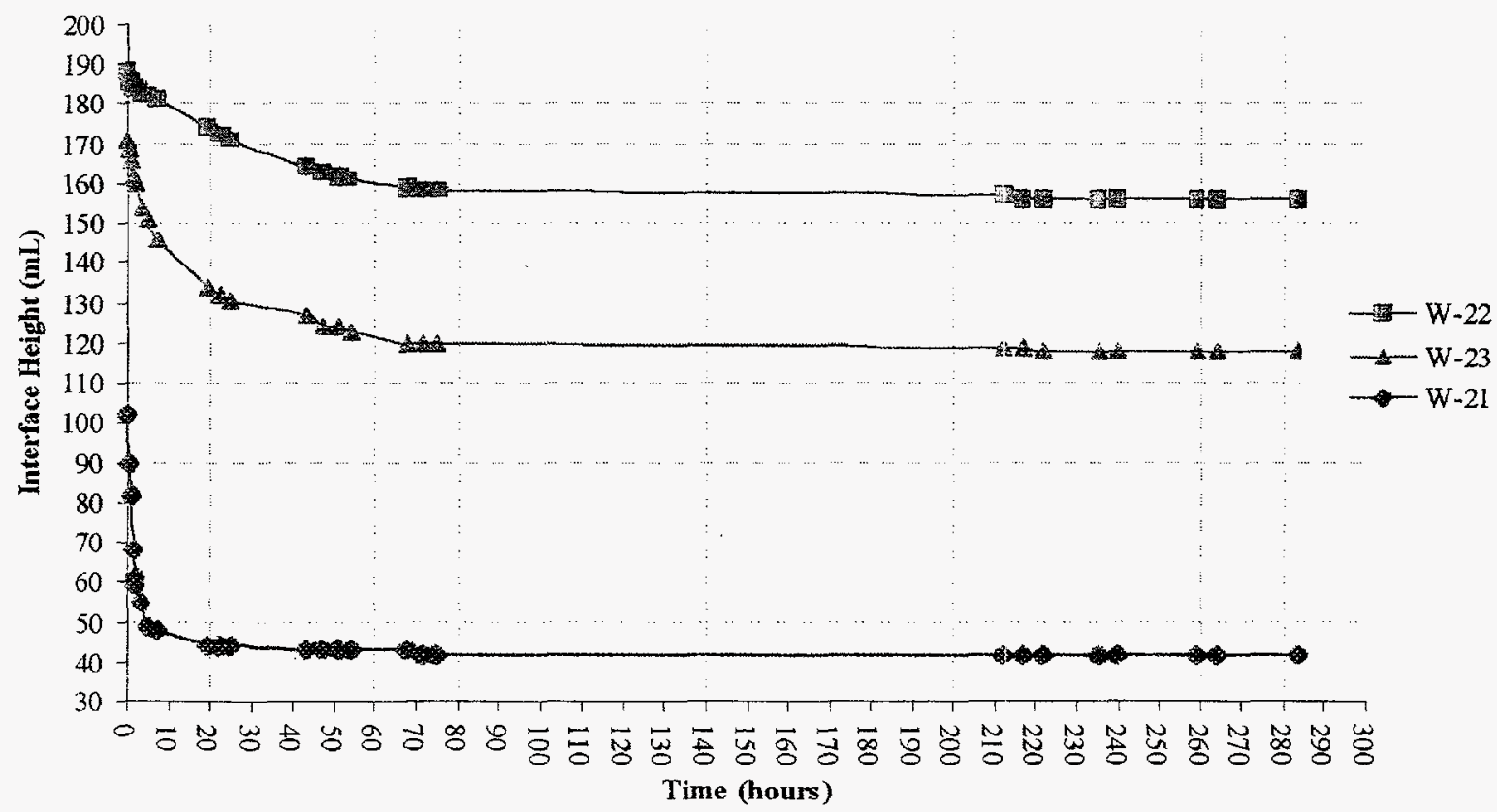


Figure 3.3 OHF Settling Rate (Relative)

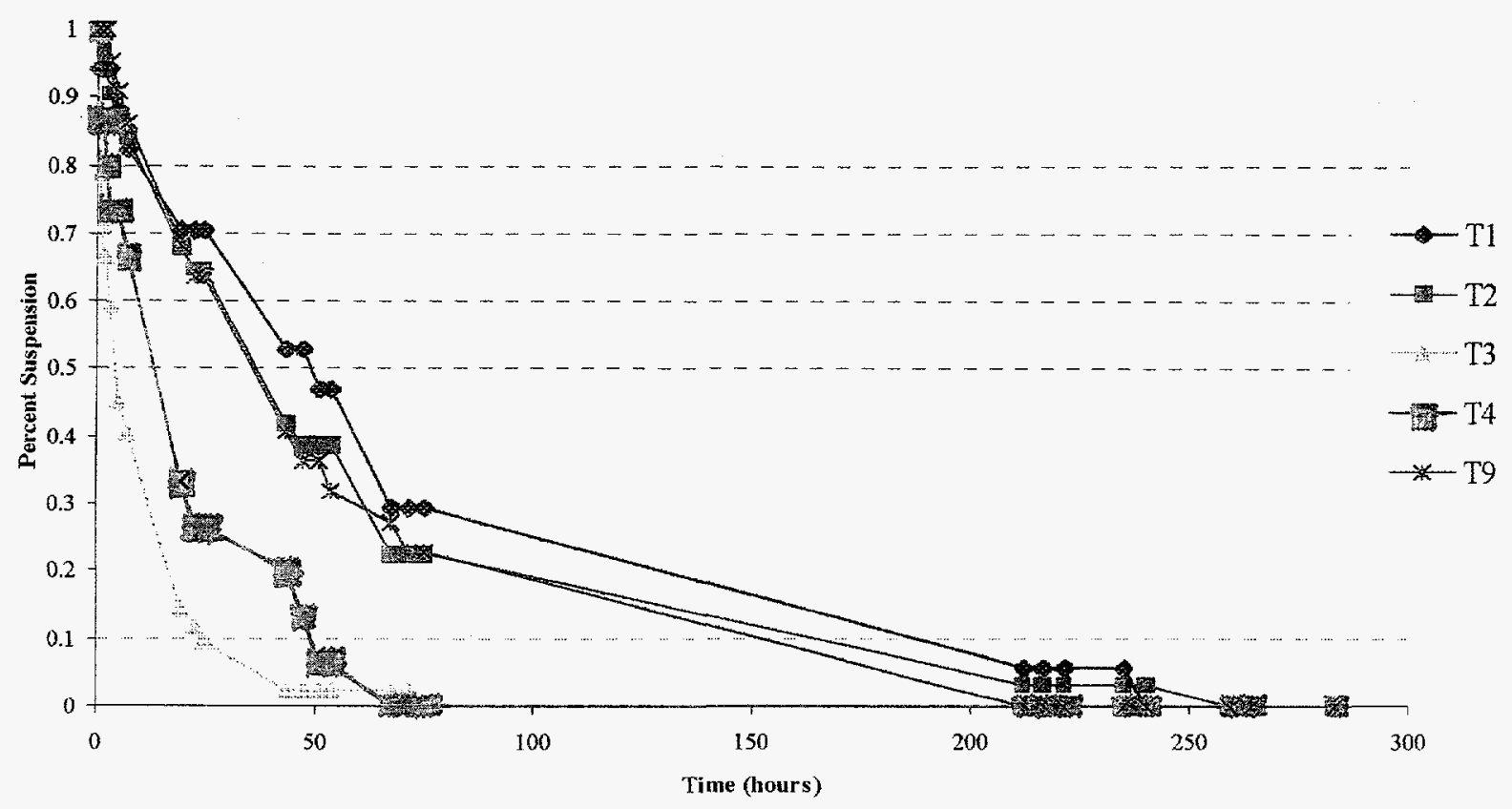

Figure 3.4 BVEST Settling Rate (Relative)

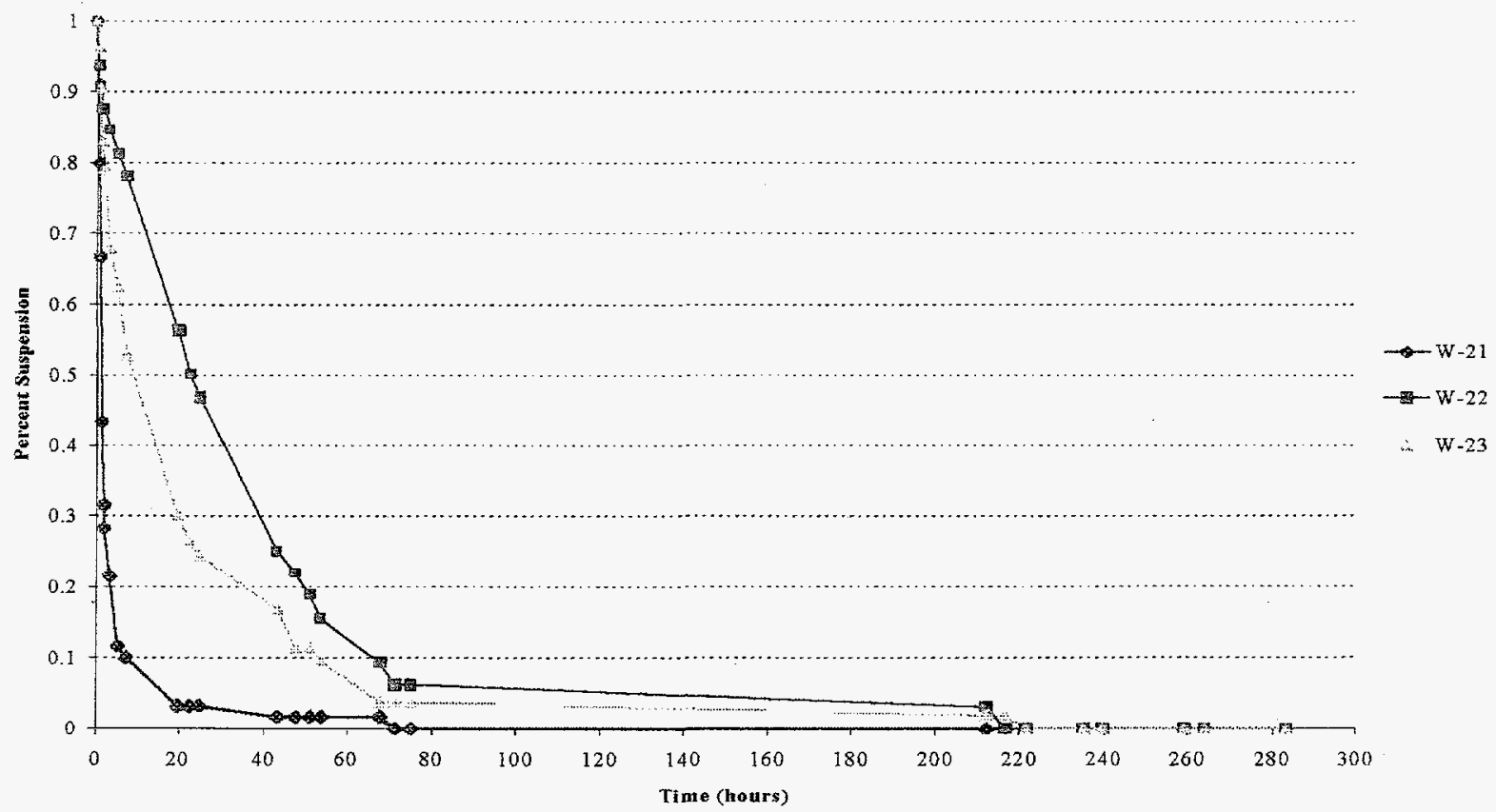




\subsection{Dry Density Measurements on the MVST Sludges}

Dried densities were obtained on the BVEST and MVST sludges. The dried densities were obtained using a Grabner Instruments Minidens system which is distributed by Petrolab Corp (874 AlbanyShaker Road, Latham, NY. 12110). This instrument uses a four place balance to accurately weigh a sample of up to 4 cubic centimeters in a sample cell. Once the weight is determined the cell is sealed off and a piston compresses the trapped air in the chamber up to a predetermined pressure (approximately $20 \mathrm{kPa}$ ) and then backs the piston off to a point where the original pressure is reached. From the resulting compression - expansion curve a volume is determined and a density of .5 to 8 $\mathrm{g} / \mathrm{cm}^{3}$ can be calculated to within $+/-.003 \mathrm{~g} / \mathrm{cm}^{3}$. Temperature is also taken into consideration in the calculations. This measurement was carried out on three dried Bethel Valley and six dried Melton Valley sludges. Results are shown in table 4.1 with the bulk wet sludge densities and calculated dry densities. All units for the above table are in $\mathrm{g} / \mathrm{ml}$.

The calculated dry densities are obtained by using the percent moisture data and assuming that all the moisture driven off has a density of water. This of course is not really true because of the organics present in the sample. They are included for comparison only.

Table 4.1

BVEST and MVST Dried Densities

\begin{tabular}{|c|c|c|c|}
\hline Tank & Density (dry) & Bulk (wet) & Calculated Dry \\
\hline (BVEST) W-21 & 1.87 & 1.36 & 1.73 \\
\hline W-22 & 1.82 & 1.16 & 1.55 \\
\hline W-23 & 2.09 & 1.57 & 2.03 \\
\hline (MVST) W-31 & 1.75 & 1.44 & 1.91 \\
\hline W-28 & 2.12 & 1.37 & 1.70 \\
\hline W-24 & 1.99 & 1.37 & 1.76 \\
\hline W-25 & 2.16 & 1.36 & 1.73 \\
\hline W-26 & 2.06 & 1.38 & 1.77 \\
\hline W-27 & 1.97 & 1.44 & 1.98 \\
\hline
\end{tabular}




\subsection{Particle Size Analysis of Selected Sludges}

Particle size characterizations were determined on OHF T-4 sludge and BVEST W-21 and W-22 sludges. The characterizations were performed using a Malvern Instruments (10 Southville Road, Southborough, MA. 01772) MicrosizerPlus particle size analyzer. The analyzer operates on the principle that incident light is reflected from a particle at a certain angle and the angle of scattering is proportional to the particle's size. A non-imaging optical system (sizing accomplished without forming an image of the particle) is used with a Helium-Neon laser at a wavelength of $633 \mathrm{~nm}$. Because the instrument is based on fundamental physical properties, the measurement is absolute with no external calibration required. For the measurement, the sample is immersed in a dispersant and passed through a sample cell whose windows are transparent to the laser light. The scattered light pattern from the sample particles is received by a custom designed detector which has a series of angular detection sectors for the determination of particle sizing. The calculated distribution is based on a set of established size classes which are optimized to match the detector geometry.

\subsection{Discussion of Instrument Theory}

\section{Optical System}

The MicrosizerPlus employs a reverse fourier optic system which allows for the measurement of smaller particles down to $0.05 \mu \mathrm{m}$. The reverse fourier system is similar to a conventional fourier system with the exception that instead of collimating the laser light onto a detector after scattering from the sample, the laser is focused onto a point on the main detector. The sample cell is placed at a fixed distance in front of the focusing lens, prior to the detector, in the converging analyzer beam. With this configuration the scattered light due to smaller particles (large angles of deflections) are received onto a "large angle detector" which is placed perpendicular to the main detector. Using this type of configuration, a range lens is not needed to collect the large scattering angles due to smaller particles and therefore aberrations in large angle scattering detection are mitigated. As stated above the scattered light pattern is received onto a custom designed detector which has a series of angular detection sectors to determine particle sizes. The light which is not scattered is focused through a 
small aperture in the main detector to a central detector. Knowing the initial laser power entering the system the central detector measures the total laser power passing out of the system allowing the sample volume concentration to be determined. The diffraction pattern remains stationary and coaxial to the detectors throughout the determination regardless of the velocity of the particles passing through the detector cell.

\section{Optical Model}

To obtain an accurate particle size distribution using light scattering principles the particle's optical properties must be accounted for. This is especially true for smaller particles dispersed in liquid or for particles which are optically transparent. The Malvern software provides the ability to account for three optical properties of the sample. These three properties are 1) the relative particle refractive index, which is the refractive index of the particle relative to the dispersant, 2) the particle refractive index, which accounts for the light absorption by the particle, and 3) the dispersant refractive index. For the measurements of the OHF and BVEST sludges the following model was used: 1.15 refractive index relative to the surrounding medium (real), $\mathbf{0 . 1}$ particle refractive index (imaginary), and a 1.33 dispersant refractive index. This equates to a total refractive index of $1.15 \times 1.33=1.53$. Due to the complex precipitation chemistry of the waste tank sludges, an accurate optical model that matches the sample particles is impossible to obtain but it is believed that the model used was sufficient. The justification for each setting in the optical model is given below.

The dispersant refractive index was chosen based on the following. Water, which is a common dispersant, has a refractive index of 1.33. To prevent the dissolution of sludge particles during the tests however, a four molar $\mathrm{NaOH}$ solution was used as the dispersant. Sodium hydroxide has a refractive index which is close to water ${ }^{6}$ and therefore the optical model with a dispersant refractive index of 1.33 was considered to be reasonable.

Choosing an imaginary particle refractive index was more difficult since the absorption properties of the solids could not be determined. The standard value of 0.1 was used in accordance with manufacturers recommendation. 
A relative refractive index of 1.15 was chosen based on the assumed sludge matrix. As the relative refractive index and particle sizes get smaller (1 um or less), the more important the model becomes. For the BVEST sludges in which the majority of the solids are believed to be precipitated calcium carbonate, the standard optical model used is believed to be sufficient. However, for OHF T-4 sludge in which there is expected to be higher levels of thorium oxide (resulting in a higher relative refractive index), the standard model would not be as accurate for the particle sizes below $1 \mathrm{um}$. However, when the T-4 data was recalculated assuming all thorium oxide, the results listed in this report did not vary by more than $20 \%$.

\subsection{Discussion of Result Interpretation and Reporting Conventions}

All distributions reported in this.document are based on the assumption that the particles are spherical in shape with a particle density of $1 \mathrm{~g} / \mathrm{cc}$. If the result values are going to be correlated to another sizing technique (such as sieving), shape corrections will need to be applied. The Malvern software has the ability to apply shape corrections and although they are not included here, it is available for those readers who desire more information.

The size distributions illustrated in figures 5.1 -5.3 and summarized in tables 5.1 - 5.4 are shown as both volume based and number based. For the volume based distributions the larger particles in the sample will dominate since they make up most of the sample volume. However, as can be seen on the frequency curves and in the tables when the distribution is determined based on number the smaller particles dominate. This illustrates that the smaller particles make up a greater percent of the population. Volume based distributions are shown in blue on the curves and number based distributions are in red.

Table 5.1 summarizes the most likely particle sizes present in the distribution for each of the tank sludges analyzed. These sizes are listed as both volume and number based. Here the model sizes are listed. The modal size is defined as the most likely diameter in the distribution. On the frequency curves the mode is read as the diameter at the peak of the curves. 
Tables 5.2 - 5.4 provide greater detail of the particle size distributions and are split into three sections. The diameter distribution percentiles, both volume and number based, are listed in the upper portion of the tables. The ten, fifty, eighty, and ninety percentiles are shown. The diameter listed for a given percentile is the maximum diameter of the respective distribution. As an example, in table 5.1 the number based diameter listed for the T-4 sludge eighty percentile distribution $(\mathrm{D}(n, 0.8))$ is $0.20 \mu \mathrm{m}$. This means that eighty percent of the particles have a diameter of $0.20 \mu \mathrm{m}$ or less. Also, note that $\mathrm{D}(x, 0.5)$ is the median diameter of the respective volume/number distribution. A.S.T.M derived diameters are listed in the middle section of the tables. Here derived diameters are shown based on the British Standard. $D[4,3]$ is the volume weighted mean diameter, $D[3,2]$ the surface weighted mean diameter, and $\mathrm{D}[1,0]$ the arithmetic mean diameter. Finally, in the bottom portion of the tables the distribution modal sizes are listed.

Table 5.1

Distribution Modal Sizes ( $\mu \mathrm{m})$

\begin{tabular}{|c|r|r|}
\hline \multirow{2}{*}{ Tank } & \multicolumn{2}{|c|}{ Distribution Modal Size } \\
\cline { 2 - 3 } & Volume Based & Number Based \\
\hline T-4 & 5.17 & 0.11 \\
\hline W-21 & 10.16 & 0.14 \\
\hline W-23 & 8.04 & 0.15 \\
\hline
\end{tabular}




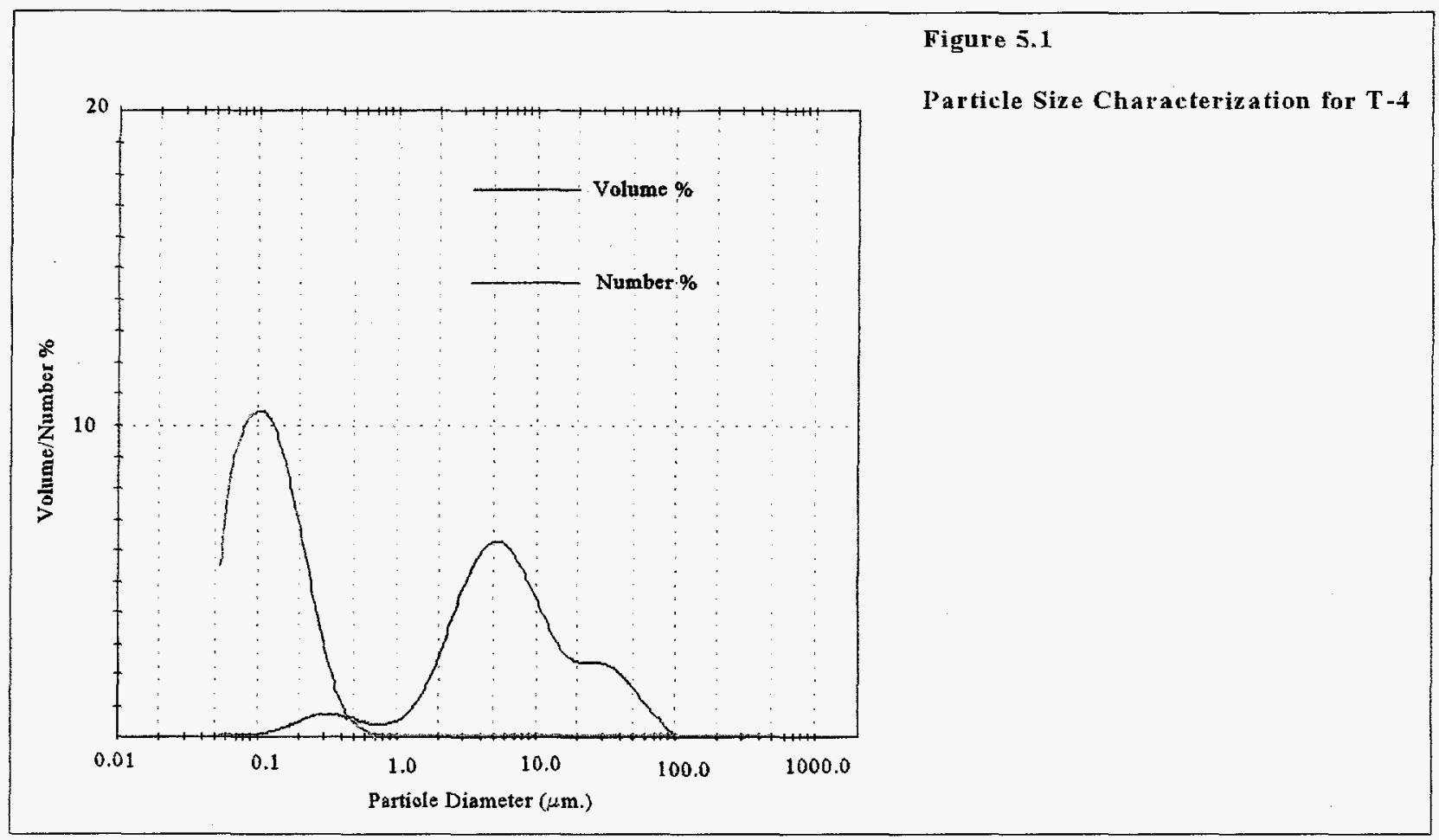

Table 5.2

T-4 Sludge Derived Diameters and Modal Size $(\mu \mathrm{m})$

\begin{tabular}{|l|c|c|}
\hline Diameter/Mode & \multicolumn{2}{|c|}{ Distribution Percentiles } \\
\hline $\mathrm{D}(x, 0.1)$ & Volume $(x=v)$ Based & Number $(x=n)$ Based \\
\hline $\mathrm{D}(x, 0.5)$ & 1.47 & 0.06 \\
\hline $\mathrm{D}(x, 0.8)$ & 5.94 & 0.12 \\
\hline $\mathrm{D}(x, 0.9)$ & 16.61 & 0.20 \\
\hline & 31.05 & 0.26 \\
\hline $\mathrm{D}[4,3]$ & A.S.T.M Derived Diameters \\
\hline $\mathrm{D}[3,2]$ & \multicolumn{2}{|c|}{11.56} \\
\hline $\mathrm{D}[1,0]$ & \multicolumn{2}{|c|}{0.19} \\
\hline
\end{tabular}




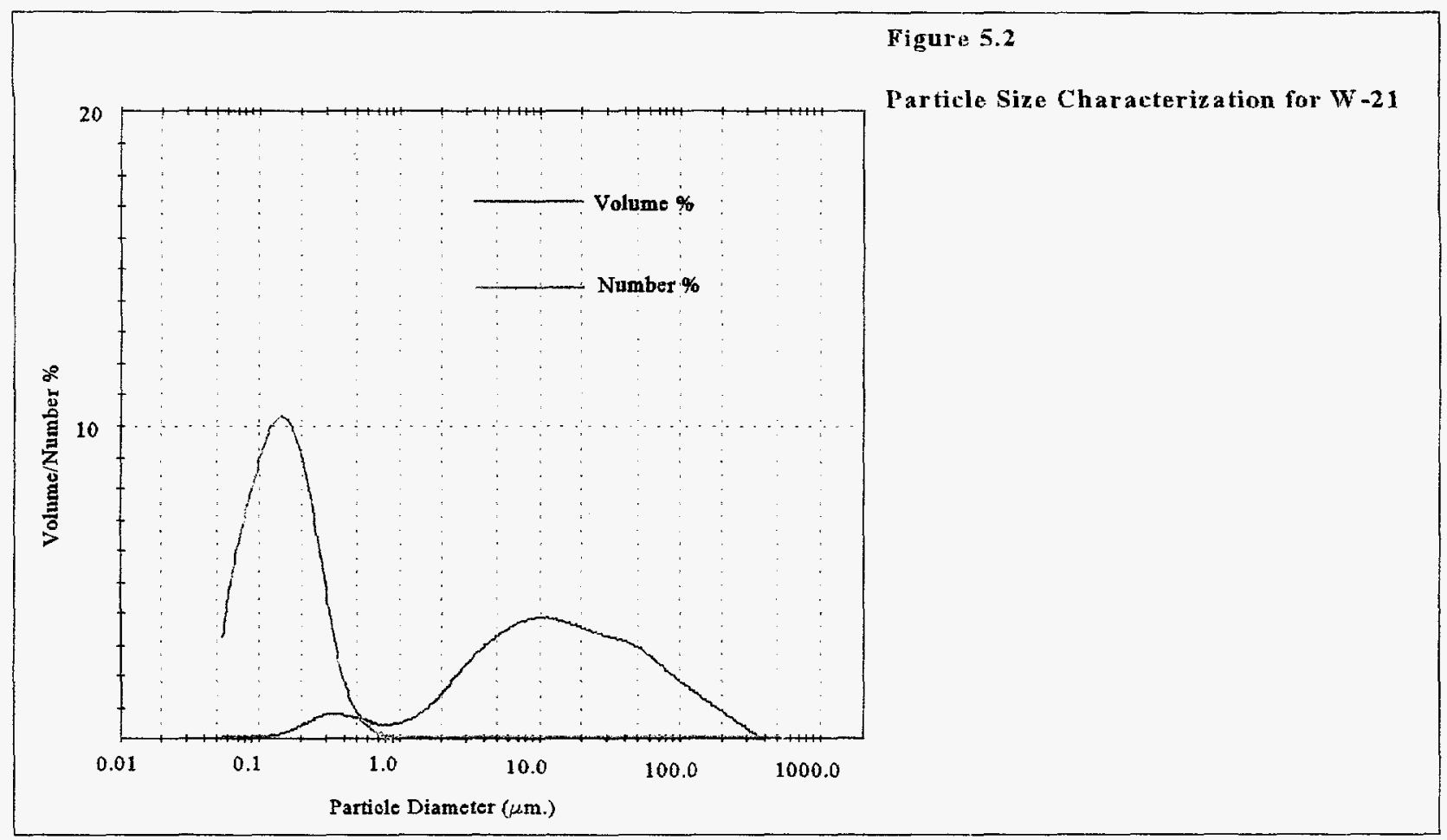

Table 5.3

W-21 Sludge Derived Diameters and Modal Size $(\mu \mathrm{m})$

\begin{tabular}{|l|c|c|}
\hline Diameter/Mode & \multicolumn{2}{|c|}{ Distribution Percentiles } \\
\hline & Volume $(x=v)$ Based & Number $(x=n)$ Based \\
\hline $\mathrm{D}(x, 0.1)$ & 1.52 & 0.07 \\
\hline $\mathrm{D}(x, 0.5)$ & 12.71 & 0.14 \\
\hline $\mathrm{D}(x, 0.8)$ & 48.21 & 0.23 \\
\hline $\mathrm{D}(x, 0.9)$ & 87.58 & 0.29 \\
\hline & A.S.T.M Derived Diameters \\
\hline $\mathrm{D}[4,3]$ & \multicolumn{2}{|c|}{32.38} \\
\hline $\mathrm{D}[3,2]$ & \multicolumn{2}{|c|}{ 2.68 } \\
\hline $\mathrm{D}[1,0]$ & \multicolumn{2}{|c|}{ Distribution Modal Size } \\
\hline & 10.16 & 0.14 \\
\hline Mode 1 & \multicolumn{2}{|c|}{} \\
\hline
\end{tabular}




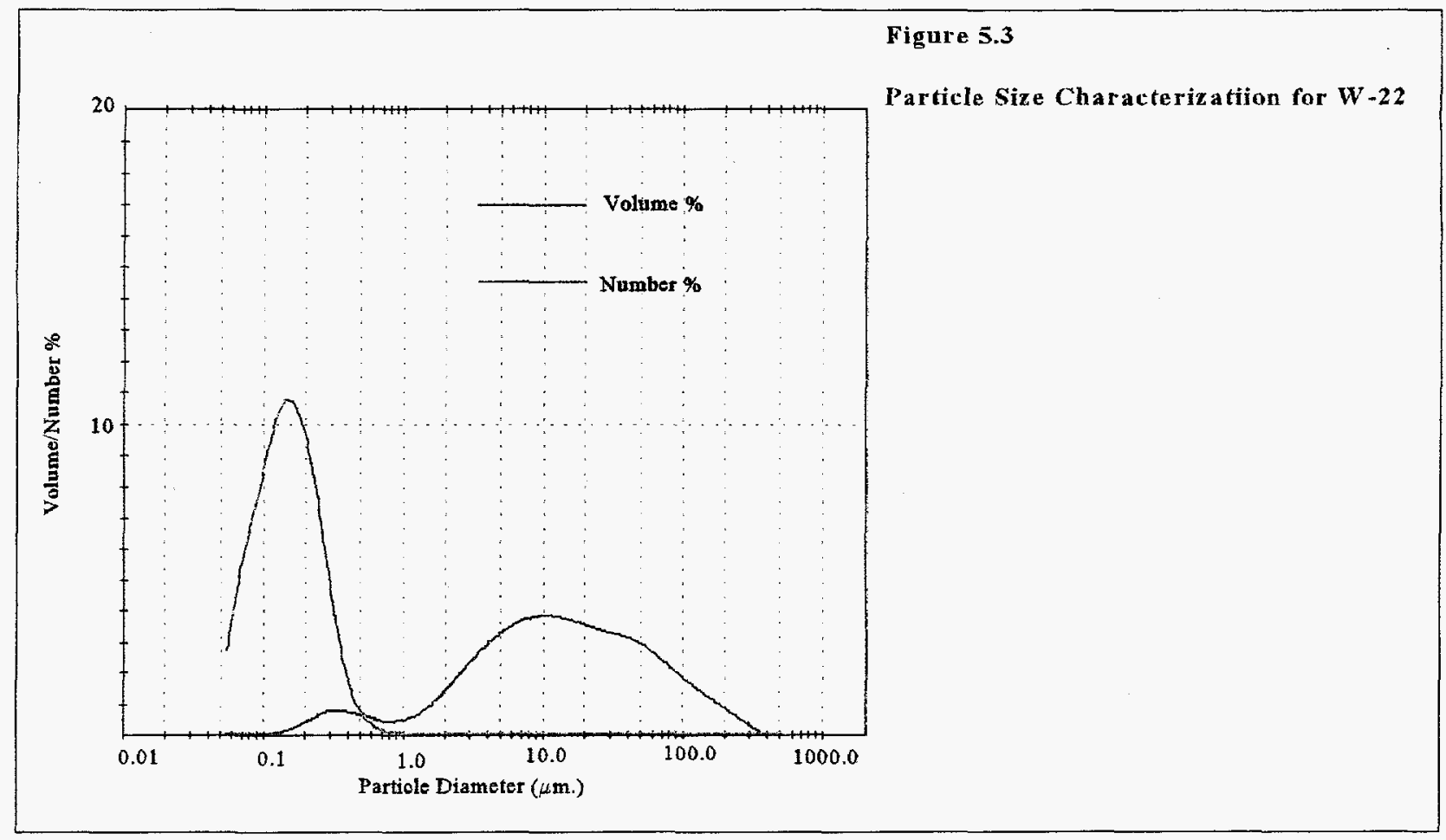

Table 5.4

W-22 Sludge Derived Diameters and Modal Size ( $\mu \mathrm{m})$

\begin{tabular}{|l|c|c|}
\hline Diameter/Mode & \multicolumn{2}{|c|}{ Distribution Percentiles } \\
\hline & Volume $(x=v)$ Based & Number $(x=n)$ Based \\
\hline $\mathrm{D}(x, 0.1)$ & 1.67 & 0.07 \\
\hline $\mathrm{D}(x, 0.5)$ & 9.33 & 0.15 \\
\hline $\mathrm{D}(x, 0.8)$ & 29.66 & 0.23 \\
\hline $\mathrm{D}(x, 0.9)$ & 50.13 & 0.30 \\
\hline & A.S.T.M Derived Diameters \\
\hline $\mathrm{D}[4,3]$ & \multicolumn{2}{|c|}{19.80} \\
\hline $\mathrm{D}[3,2]$ & \multicolumn{2}{|c|}{ 2.77 } \\
\hline $\mathrm{D}[1,0]$ & \multicolumn{2}{|c|}{0.18} \\
\hline & Distribution Modal Size \\
\hline Mode 1 & 8.04 & 0.15 \\
\hline
\end{tabular}


• 


\subsection{Analysis of Selected MVST Supernants for Hydroxylamines}

Due to the recent concerns about the hazards associated with hydroxylamine, selected waste tank supernants were analyzed for its presence. Hydroxylamine is very soluble in water and undergoes rapid decomposition at room temperature especially in the presence of atmospheric moisture and carbon dioxide. Test have shown that detonation occurs when heated in a test tube ${ }^{6}$. Five MVST waste tank supernants were chosen for the analysis (W-24, W-26, W-27, W-28, and W-31).

The analyses were performed using a Dionex Model $4500 \mathrm{i}$ ion chromatography system configured with a Dionex IonPac ${ }^{\circledR} \mathrm{CS} 12$ cation exchange column plumbed to a electrochemical detector. The detector utilized a platinum working electrode with a constant positive $0.8 \mathrm{VDC}$ applied throughout the analytical run. Electrochemical detection was ideal for the analysis due to the fact that hydroxylamine is such a strong reducer (ie. is easily oxidized) and detector voltages could be set to eliminate the interferences from other major cations that exhibit similar retention times on the column as hydroxylamine.

The results were obtained using a ten fold dilution of the supernates using type II water as the diluant. The final corrected values of the analysis are summarized in table 6.1.

\section{Table 6.1 Hydroxylamine Content of Selected MVST Supernants}

\begin{tabular}{||c|c|c|}
\hline Tank & $\begin{array}{c}\text { Results } \\
\text { (ug/ml) }\end{array}$ & $\begin{array}{c}+/- \\
(\mathrm{ug} / \mathrm{ml})\end{array}$ \\
\hline $\mathrm{W}-24$ & 0.78 & 0.23 \\
\hline $\mathrm{W}-26$ & 0.86 & 0.26 \\
\hline $\mathrm{W}-27$ & 0.30 & 0.09 \\
\hline $\mathrm{W}-28$ & 0.97 & 0.29 \\
\hline $\mathrm{W}-31$ & 1.15 & 0.34 \\
\hline
\end{tabular}




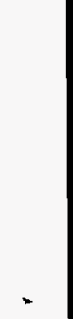

$-$ 


\subsection{Restated BVEST Sludge Viscosity}

The viscosity data presented here was initially reported in reference 2 and was collected for the purpose of obtaining a simple and rapid estimate of flow properties for the BVEST sludges. The sludge samples used for these tests were highly heterogeneous and contained coarse particles, both of these sample characteristics would degrade the rheometry measurements. The interpretation of the data presented in this section is left to the user of this document. For the reader's convenience there are some basic principles and definitions concerning rheometry measurements on sludge and slurry samples presented in Appendix A. For the data presented, no reduction was performed nor were any mathematical corrections or curve fitting/smoothing parameters applied to the data. The data is presented as measured directly from the instrument with the parameters listed in this document. All of the data presented here is on file at the RMAL and is available for further study and analysis for those readers who desire more information.

Originally, the viscosity data restated here was presented in reference 2 as true viscosity which is the slope of the tangent at any point on the flow curve. This value varies across the range of shear rates measured and results in plots with a significant amount of noise in the data. Although true viscosity quantifies the viscosity value of a non-Newtonian fluid as a Newtonian fluid at any particular shear rate the widely varying values across the range of shear rates measured results in data that is difficult to interpret. A more conventional way to express viscosity is as apparent viscosity. Apparent viscosity is calculated from a single point on the flow curve (a single shear rate) and is defined as the slope of the tangent on the flow curve at which a Newtonian flow curve (which is a straight line) intersects the non-Newtonian curve. The BVEST sludge composites are restated here using apparent viscosity vs. shear rate. The flow curves are also included to clarify the breaks in the curves that occur between shear rates of $200 \mathrm{~s}^{-1}$ to $300 \mathrm{~s}^{-1}$. These breaks are due to the samples transition from laminar flow to turbulent flow in the sensor and marks limits to the shear rates that can be used during the tests. Any data obtained after the transition to turbulent flow is suspect.

The viscosity data was collected for each of the BVEST sludges utilizing a Rotovisco RV30 Searle type rotational CR (controlled rate) rheometer, available from Gebrueder HAAKE GmbH, Karlsruhe or HAAKE (USA). The Searle type measuring system is comprised of a calibrated spring whose 
deflection is proportional to the torque and converted by a transducer to an electronic signal. The system is close to friction free and provides an instantaneous response. Viscosity and flow curves were generated using an immersion system comprised of an immersion tube and a modified HAAKE MV DIN rotor. The hollow immersion tube has an inner diameter of $42 \mathrm{~mm}$ and the modified cylindrical MV DIN rotor, which is placed within the tube, a diameter of $36.8 \mathrm{~mm}$. This leaves an annular distance of $5.2 \mathrm{~mm}$ between the rotor and tube wall for the sample to flow during the test. Without the modification to the rotor $(36.4 \mathrm{~mm}$ vs. $38.7 \mathrm{~mm}$ ) this annular distance would have only been $3.3 \mathrm{~mm}$. The annular distance was enlarged to minimize the bias due to the enactment of large particles within the sludges on the flow measurements.

All tests were conducted in a hot cell. The sensors and measuring system were located in the cell and connected to a control unit outside of the cell. A personal computer connected to the control unit was used to run the rheometer software, set test parameters, and collect data. Samples for viscosity measurements were kept at a constant temperature during the tests utilizing a plexiglass bath located in the cell with cooling coils that were supplied from a temperature controlled water bath located outside of the cell.

The viscosity and flow curves were measured on a composite of two sludge cores that were sampled from each tank. After an initial shear strength test on each core the two cores from each respective tank were composited, mixed, and diluted with the tank's supernatant at an approximate ratio of 1:1. From this mixed dilution, an aliquot was removed for total solids and undissolved solids determination. Subsequently, the viscosity and flow characteristics were measured over a range of increasing $\left(0.0 \mathrm{~s}^{-1}\right.$ to $\left.450 \mathrm{~s}^{-1}\right)$ to decreasing $\left(450 \mathrm{~s}^{-1}\right.$ to $\left.0.0 \mathrm{~s}^{-1}\right)$ shear rates. A time interval of three minutes was chosen for both the increasing and decreasing shear rate steps, for a total of six minutes per test. The temperature throughout the tests was maintained at $25^{\circ} \mathrm{C} \pm 1{ }^{\circ} \mathrm{C}$ unless otherwise noted on the curves. During the temperature stabilization process, each sample was stirred to suspend the slurry for the test. Typically this process took approximately $10 \mathrm{~min}$. to complete. Once at temperature, the sensor was lowered into the sample and the measurements were begun. The samples were stirred throughout the tests to ensure that the particles were maintained in suspension. There were however, tests conducted to compare the measured viscosity with and without sample stirring during the measurement cycle. These test were done on both standards and the W-22 sludge sample. 
The viscosities obtained on the standard solutions were comparable with and without stirring. The "no mixing" results on W-22 are presented along with the stirred results for comparison purposes.

The increasing shear rate or "Up curve" data $\left(0.0 \mathrm{~s}^{-1}\right.$ to $450 \mathrm{~s}^{-1}$ shear rates in three minutes) is depicted as a thin blue line on the graphs. The decreasing shear rate or "Down curve" data $\left(450 \mathrm{~s}^{-1}\right.$ to $0.0 \mathrm{~s}^{-1}$ shear rates in three minutes) as a thick red line. 
Figure 7.1 Apparent Viscosity vs. Shear Rate for W-21 Sludge Composite

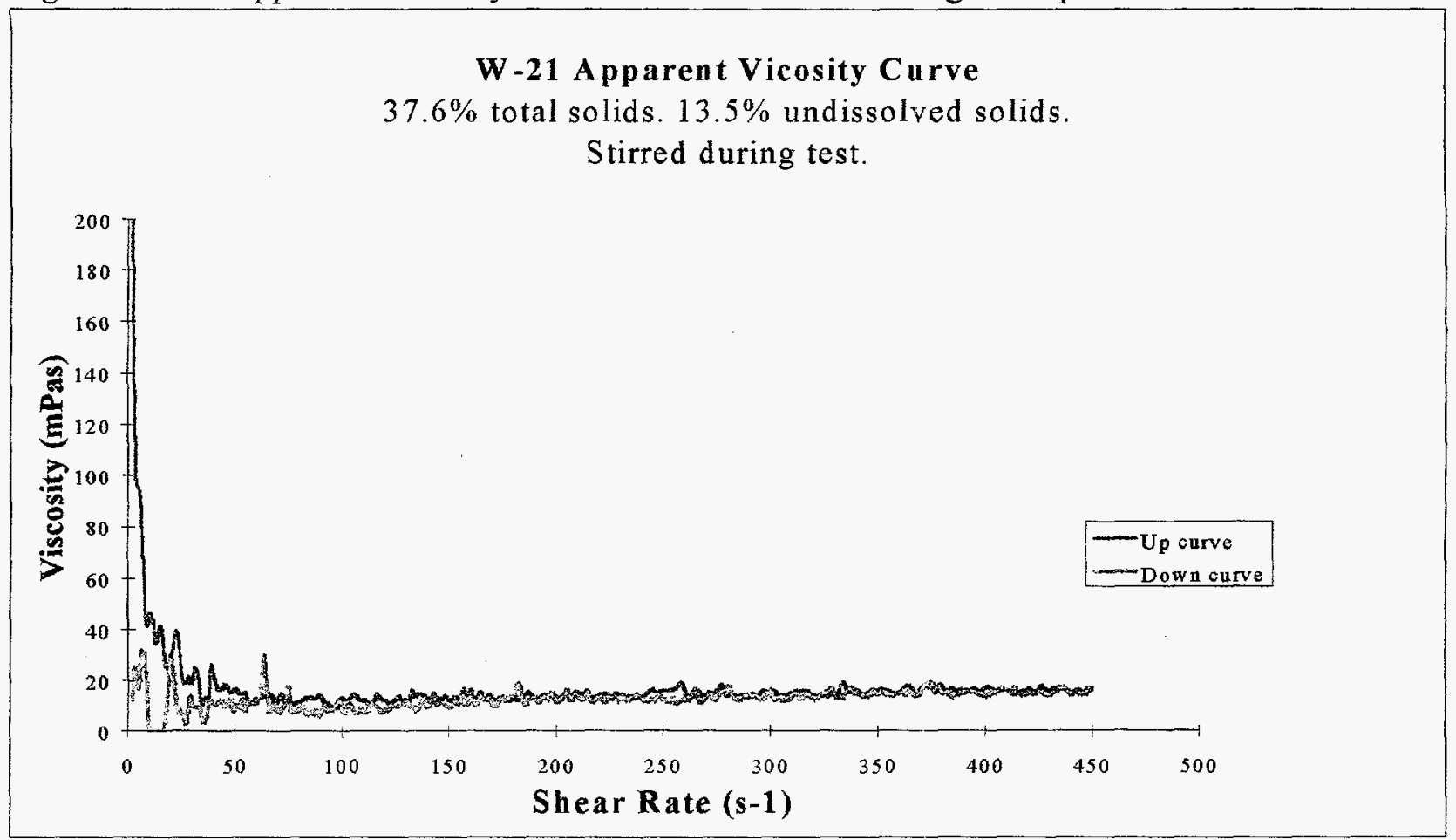

Figure 7.2 Shear Stress vs. Shear Rate for W-21 Sludge Composite

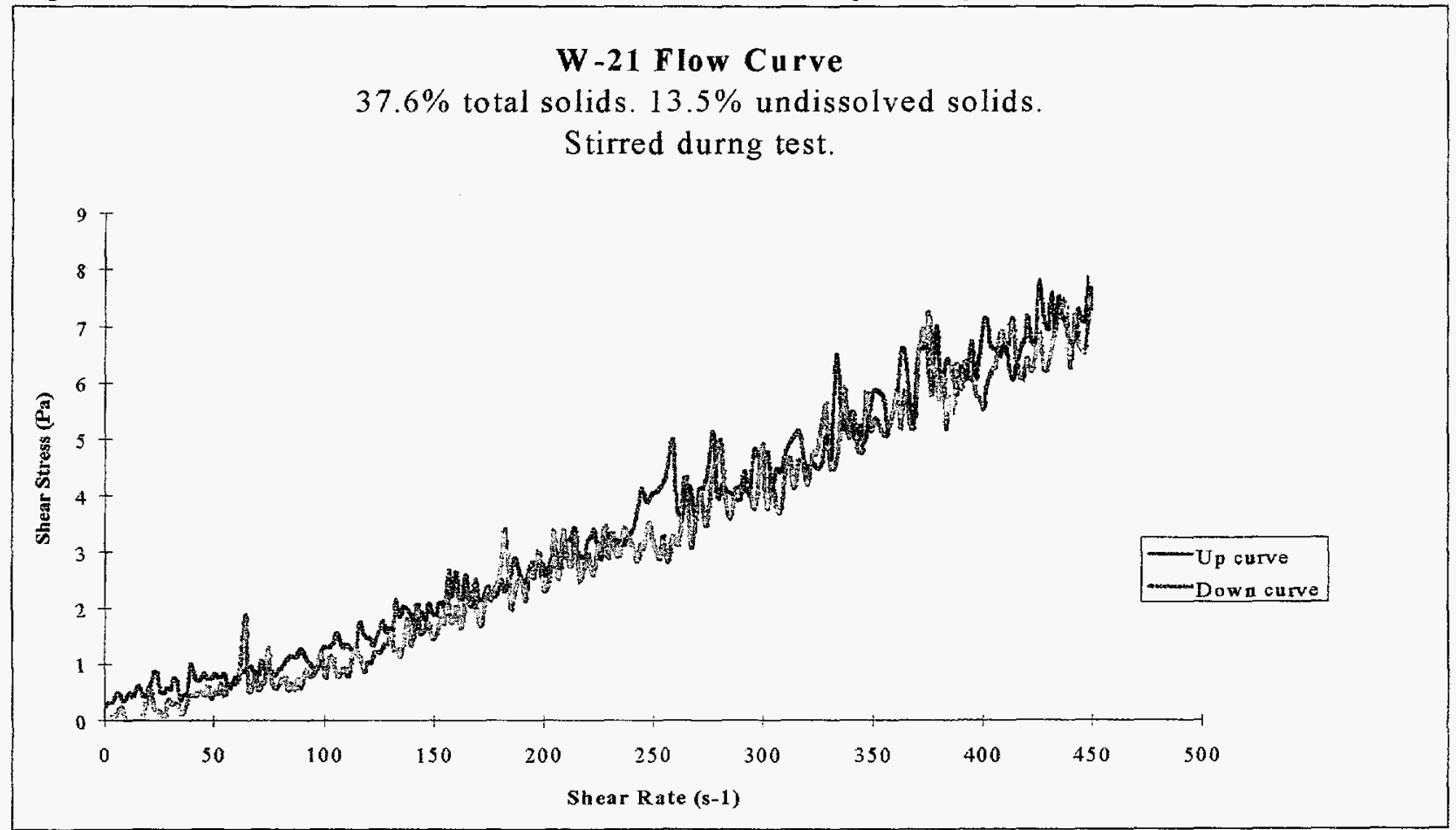


Figure 7.3 Apparent Viscosity vs. Shear Rate for W-22 Sludge Composite

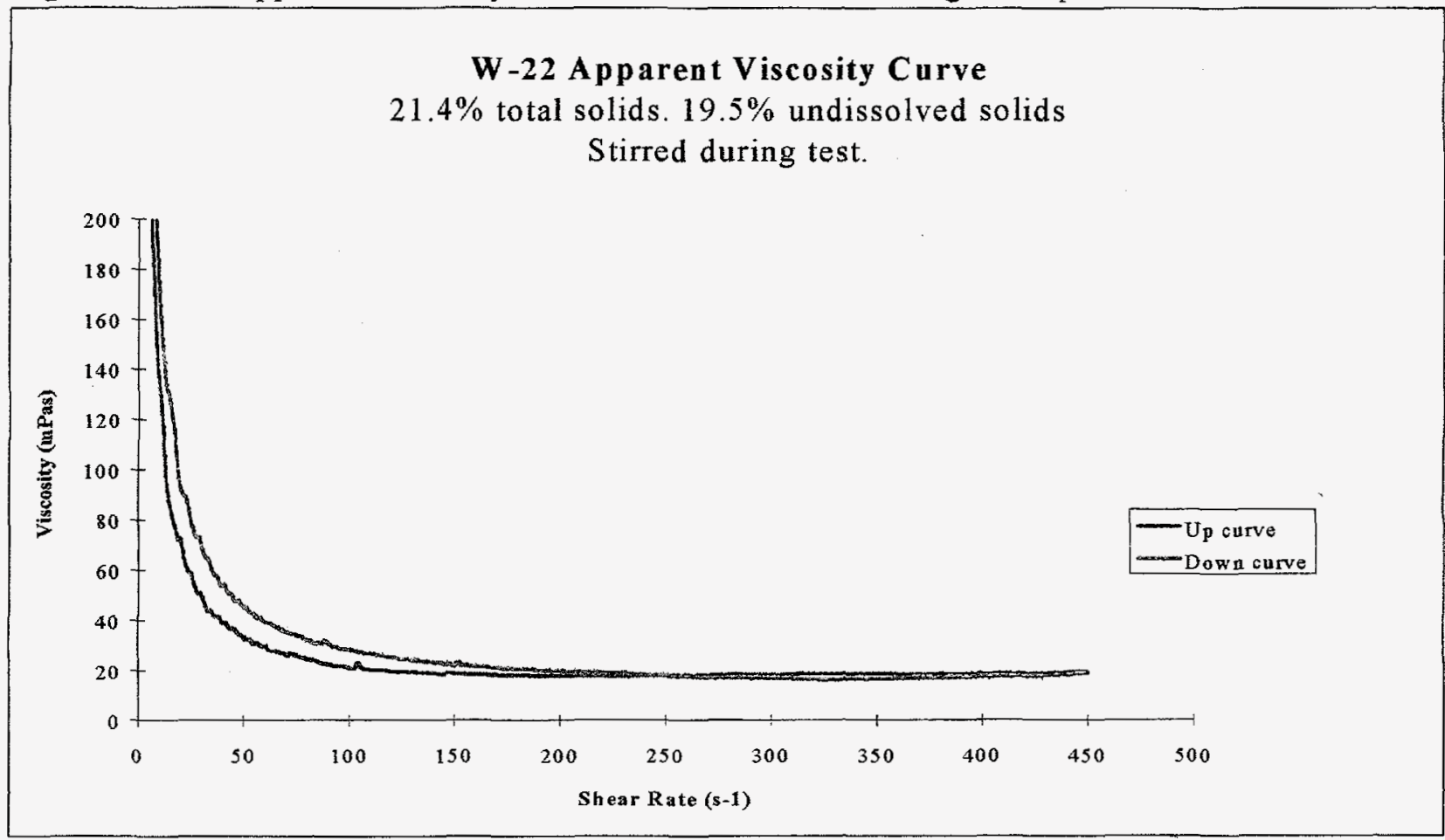

Figure 7.4 Shear Stress vs. Shear Rate for W-22 Sludge Composite

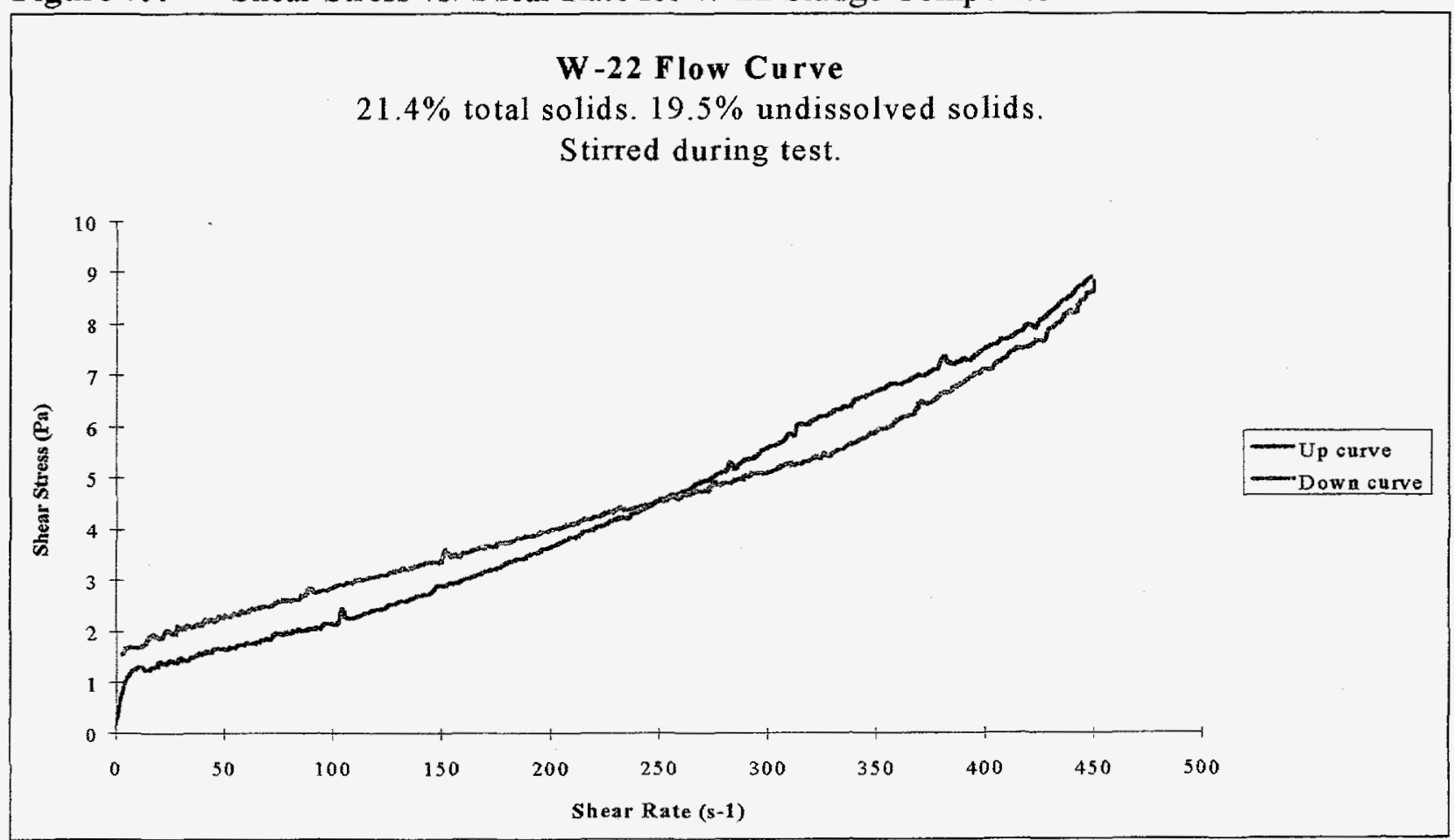


Figure 7.5 Apparent Viscosity vs. Shear Rate for W-22 Sludge Composite (Duplicate)

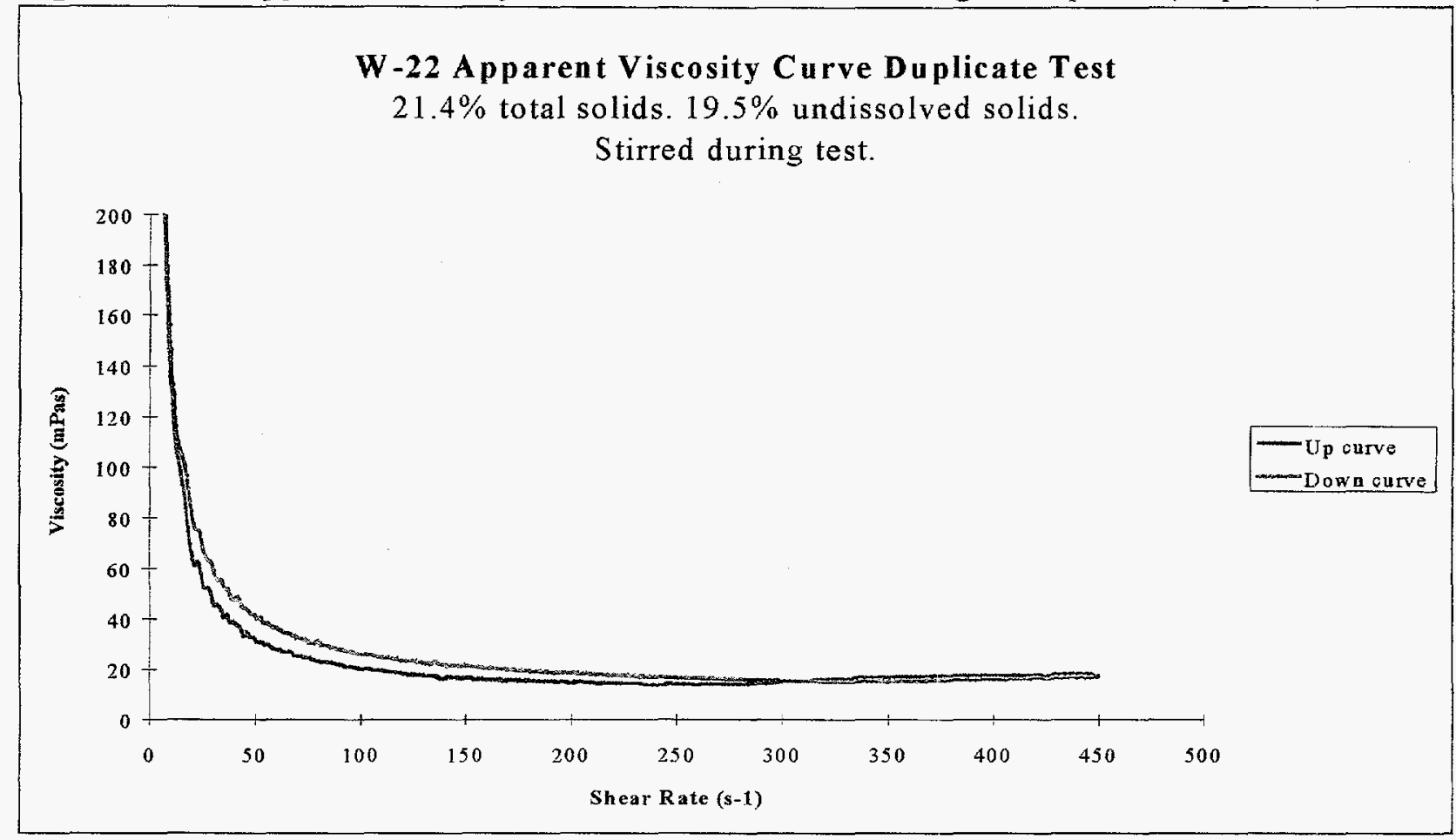

Figure 7.6 Shear Stress vs. Shear Rate for W-22 Sludge Composite (Duplicate)

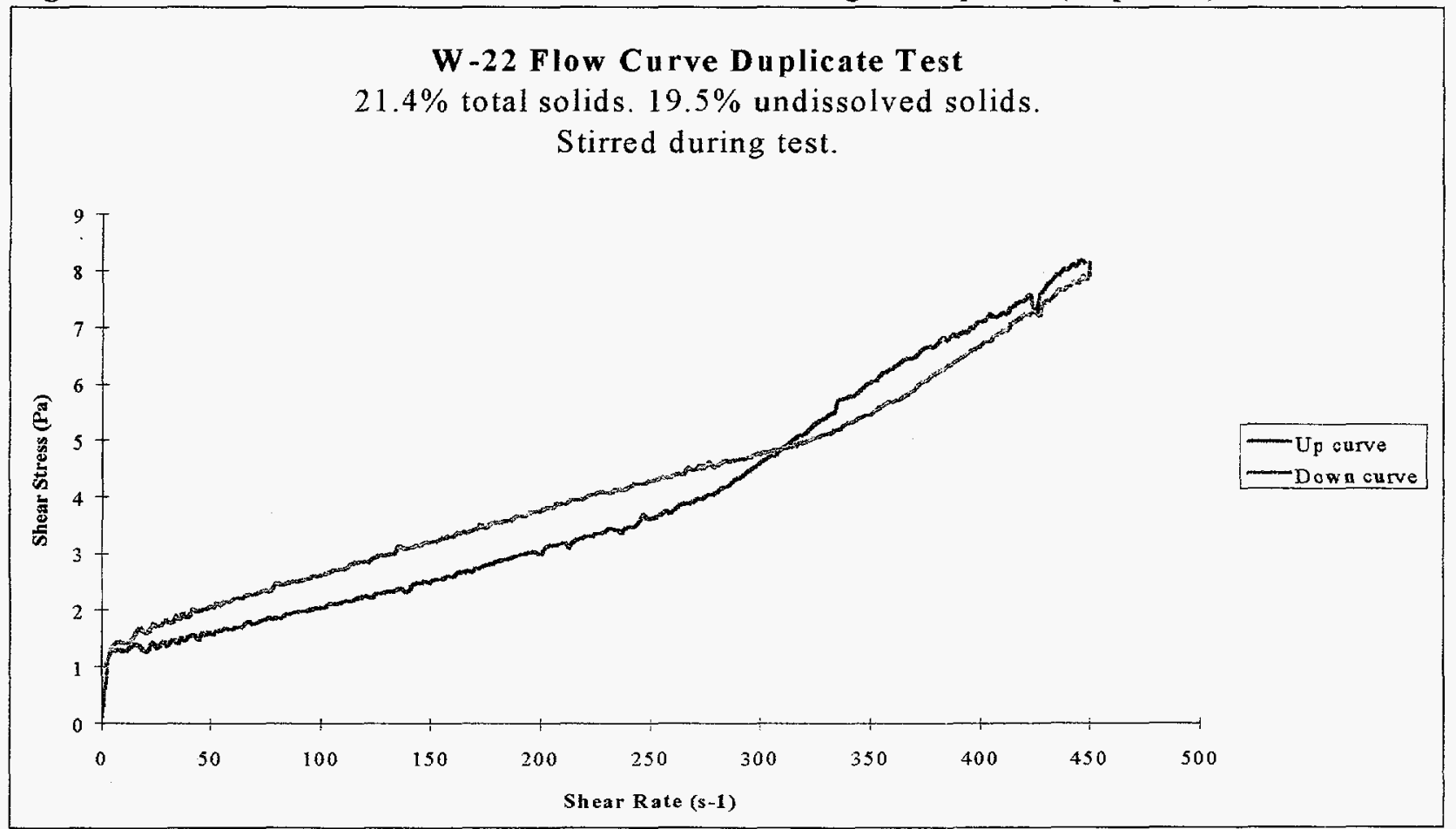


Figure 7.7 Apparent Viscosity vs. Shear Rate for W-22 Sludge Composite (Static)

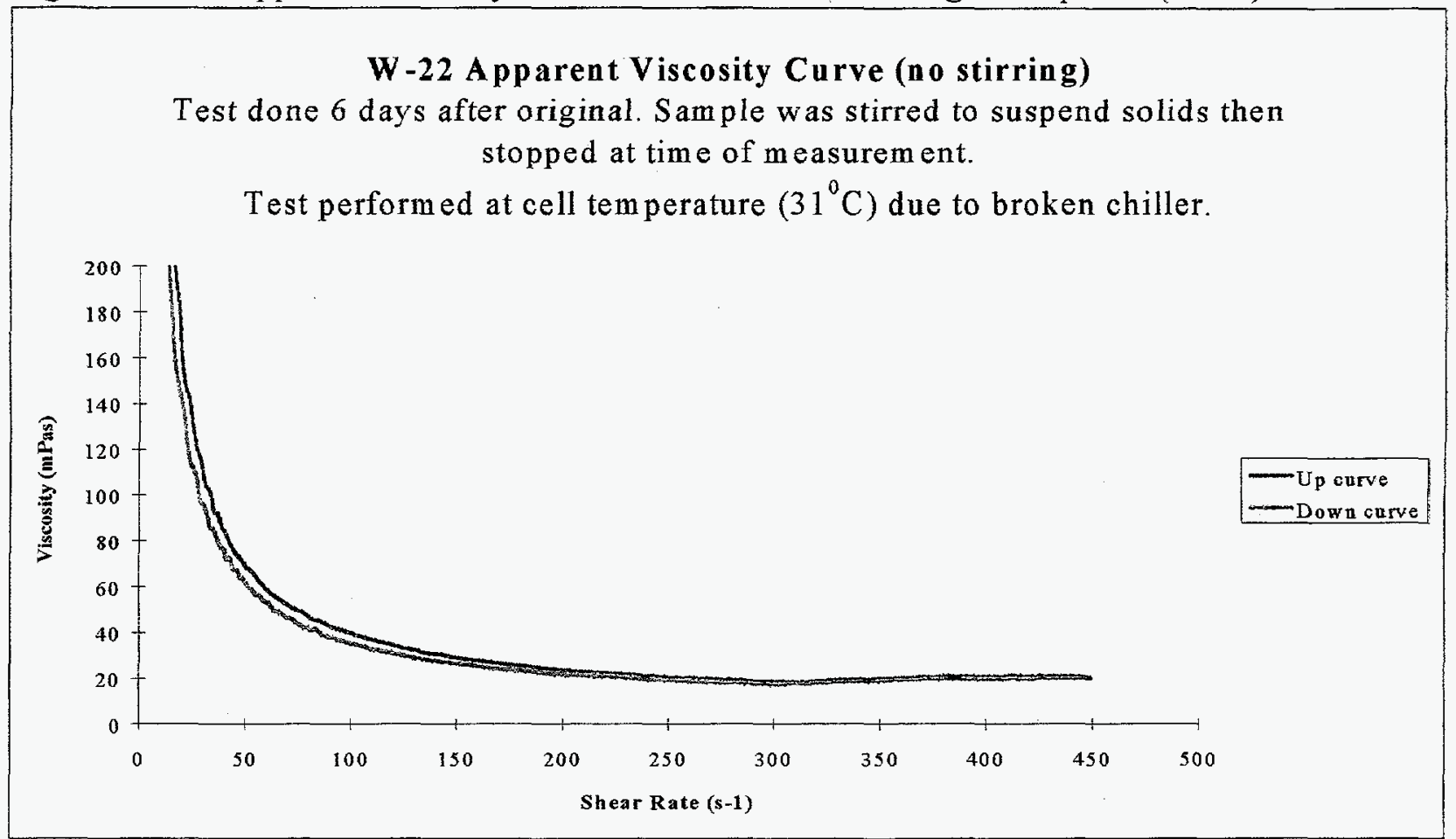

Figure 7.8 Shear Stress vs. Shear Rate for W-22 Sludge Composite (Static)

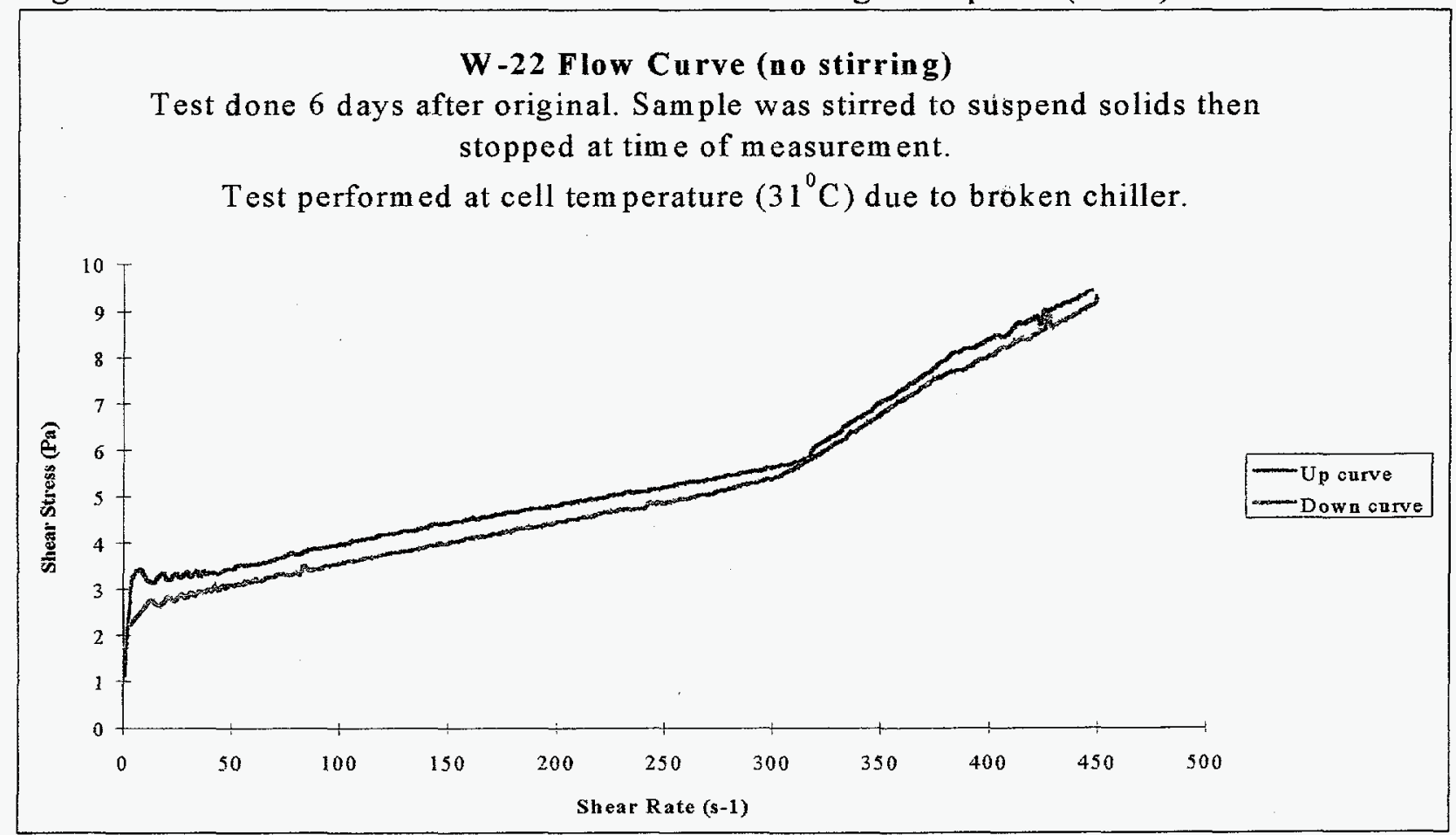


Figure 7.9 Apparent Viscosity vs. Shear Rate for W-23 Sludge Composite

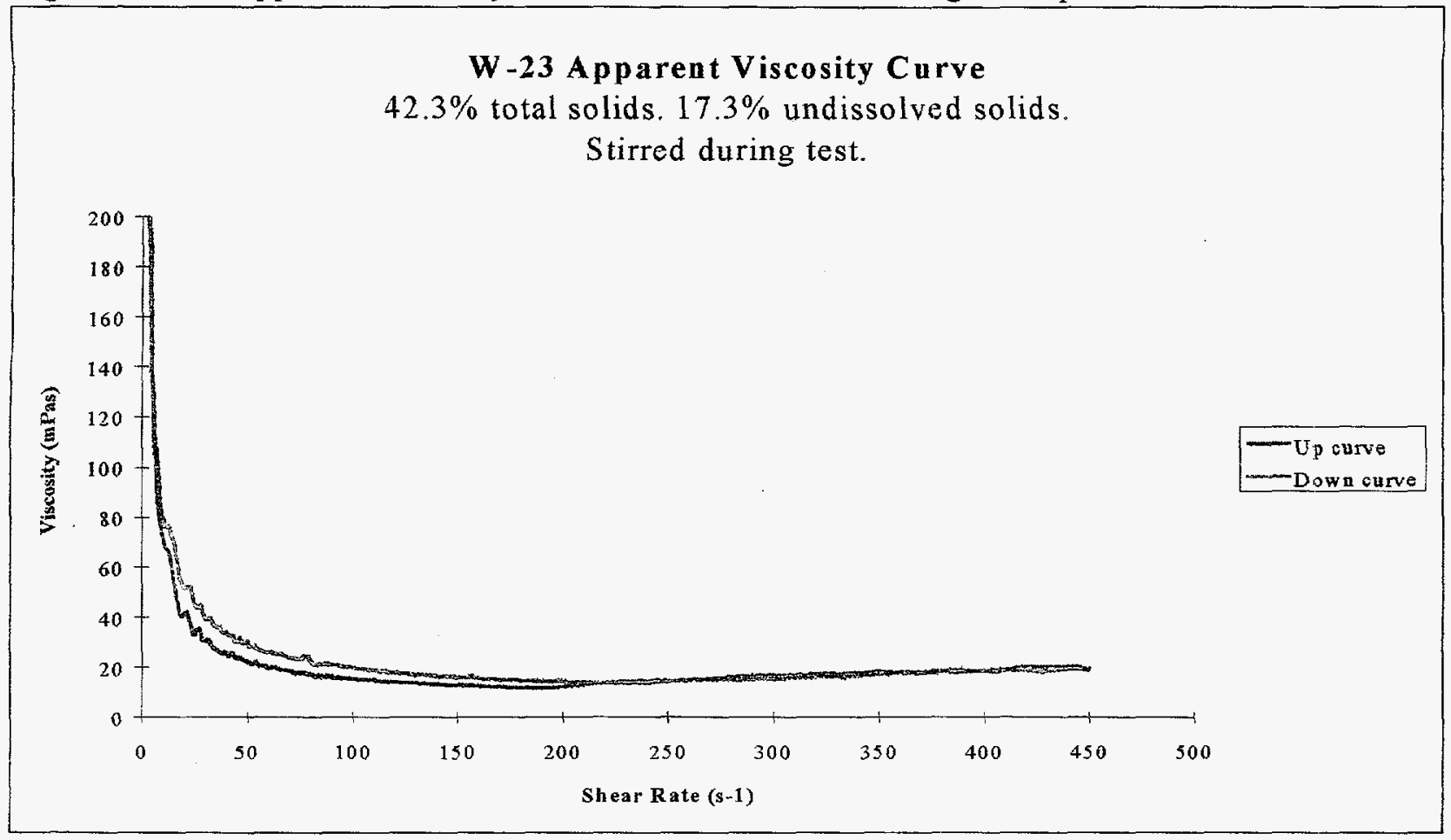

Figure 7.10 Shear Stress vs. Shear Rate for W-23 Sludge Composite

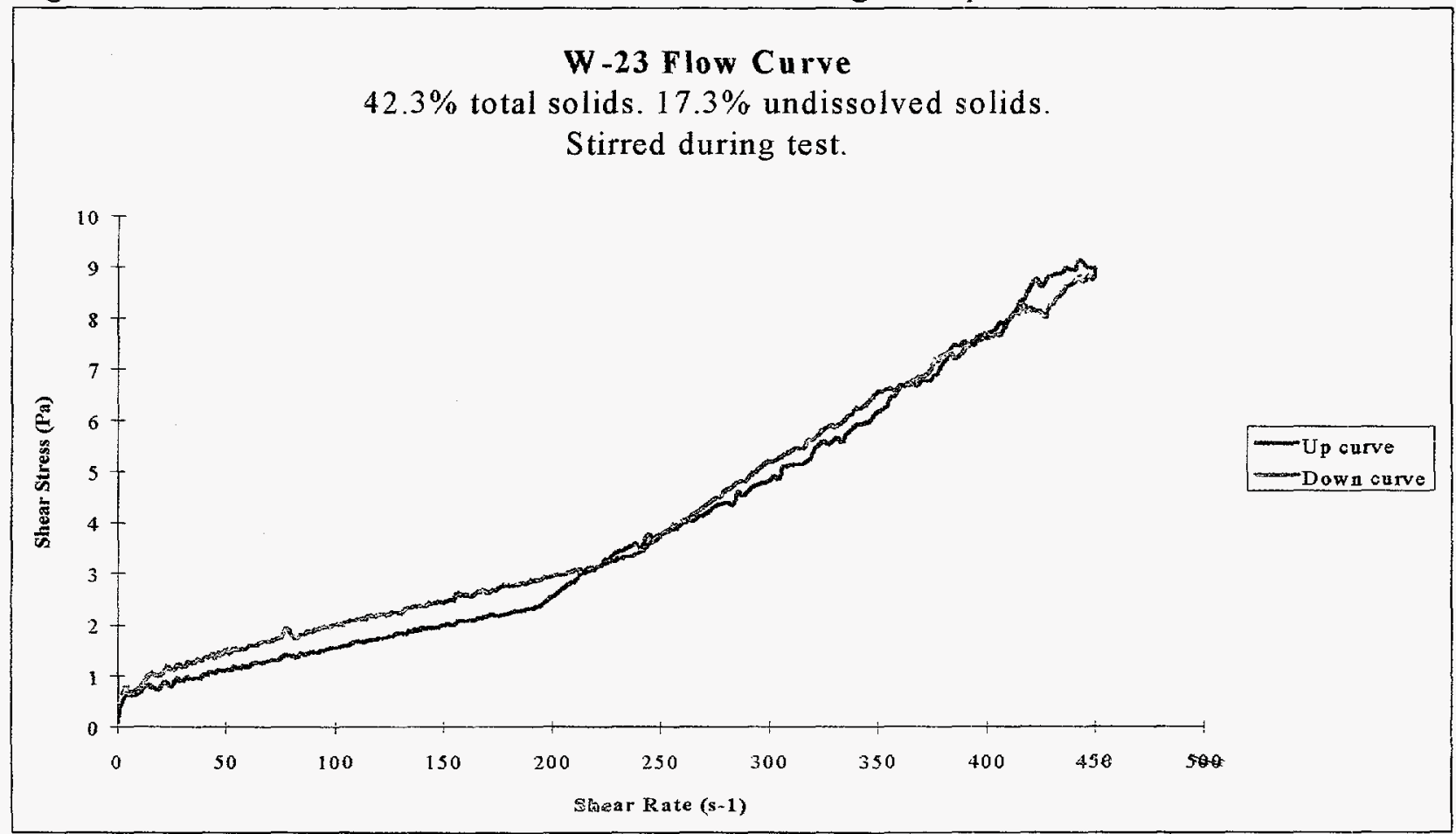




\section{REFERENCES}

1. J. M. Keller, J. M. Giaquinto, and A. M. Meeks, Characterization of the MVST Waste Tanks Located at ORNL, ORNL/TM-13357, December 1996.

2. J. M. Keller, J. M. Giaquinto, and A. M. Meeks, Characterization of the BVEST Waste Tanks Located at ORNL, ORNL/TM-13358, January 1997.

3. J. M. Keller, J. M. Giaquinto, and A. M. Meeks, Characterization of the Old Hydrofracture Facility (OHF) Waste Tanks Located at ORNL, April 1997.

4. W. T. Mullins and G. W. Leddicotte, The Radiochemistry of Phosphorus, National Academy of Sciences - National Research Council, 1962).

5. R. C. Weast, M. J. Astle, and W. H. Beyer, CRC Handbook of Chemistry and Physics, $69^{\text {th }}$ Edition (CRC Press, Inc., Boca Raton, FL, 1988), p. B-131.

6. S. Budavari, M. J. O'Neil, A. Smith, et al., Merck Index, $12^{\text {th }}$ Edition (Merck Research Laboratories, Whitehouse Station, NJ, 1996), p. 4877. 


\section{APPENDIX A}

\section{Introduction to Rheological Models for Sludge Flow Behavior}

The mathematical models that describe the sludge flow behavior and the definition of some common terms used in Rheometry are discussed in this section. The cohesive behavior of a sludge in an undisturbed state can be considered to be a pseudo-solid. In order to mobilize and pump the sludge as a slurry some force must be applied to the undisturbed sludge to go from the pseudo-solid state to a viscous fluid or slurry state. A measure of this force required to transform the sludge into a fluid state is defined as the shear strength $\left(\tau_{\mathrm{s}}\right)$.

The shear stress/shear rate or flow behavior for non-Newtonian fluids can be described by the power law model as follows,

$$
\tau=k \dot{\gamma}^{n}
$$

where,

$$
\begin{array}{ll}
\mathrm{k}= & \text { consistency index }\left(\mathrm{Pa}-\mathrm{s}^{\mathrm{n}}\right) \\
\mathrm{n}= & \text { flow behavior index } \\
\tau= & \text { shear stress }(\mathrm{Pa}), \text { and } \\
\gamma= & \text { shear rate }\left(\mathrm{s}^{-1}\right) .
\end{array}
$$

If the flow behavior index, $\mathrm{n}=1$, the fluid is defined as Newtonian (ideal); if $\mathrm{n}<1$, the fluid is pseudoplastic; and if $\mathrm{n}>1$, the fluid shows dilatant behavior. The shear stress/shear rate behavior of these fluids are illustrated in Fig. A1. Many non-Newtonian fluids, such as a sludge slurry, require some minimum shear stress to flow. This shear stress needed to initiate flow is called the yield stress $\left(\tau_{y}\right)$, and fluids that display this behavior can be described by a modified form of the power law model:

$$
\tau=k \dot{\gamma}^{n}+\tau_{y}
$$


As illustrated in Fig. A2, the shear stress/shear rate flow curves for the modified power law behavior is very similar to the curves in Fig. A1, but are displaced from the origin by an amount equal to the yield stress. 
Figure A1 Example Rheograms for Non-Newtonian Fluids without Yield Stress

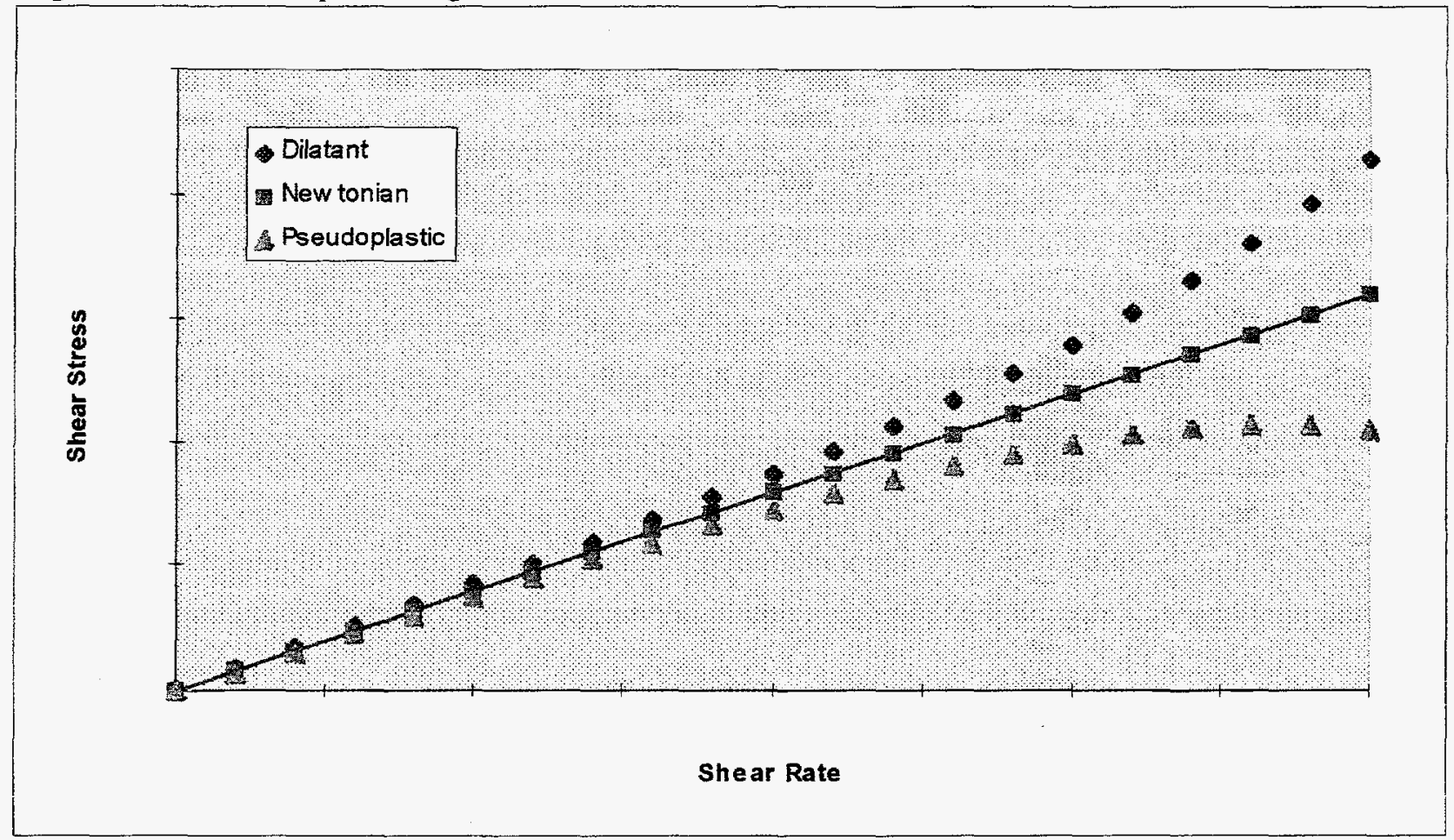

Figure A2 Example of Rheograms for Non-Newtonian Fluids with Yield Stress

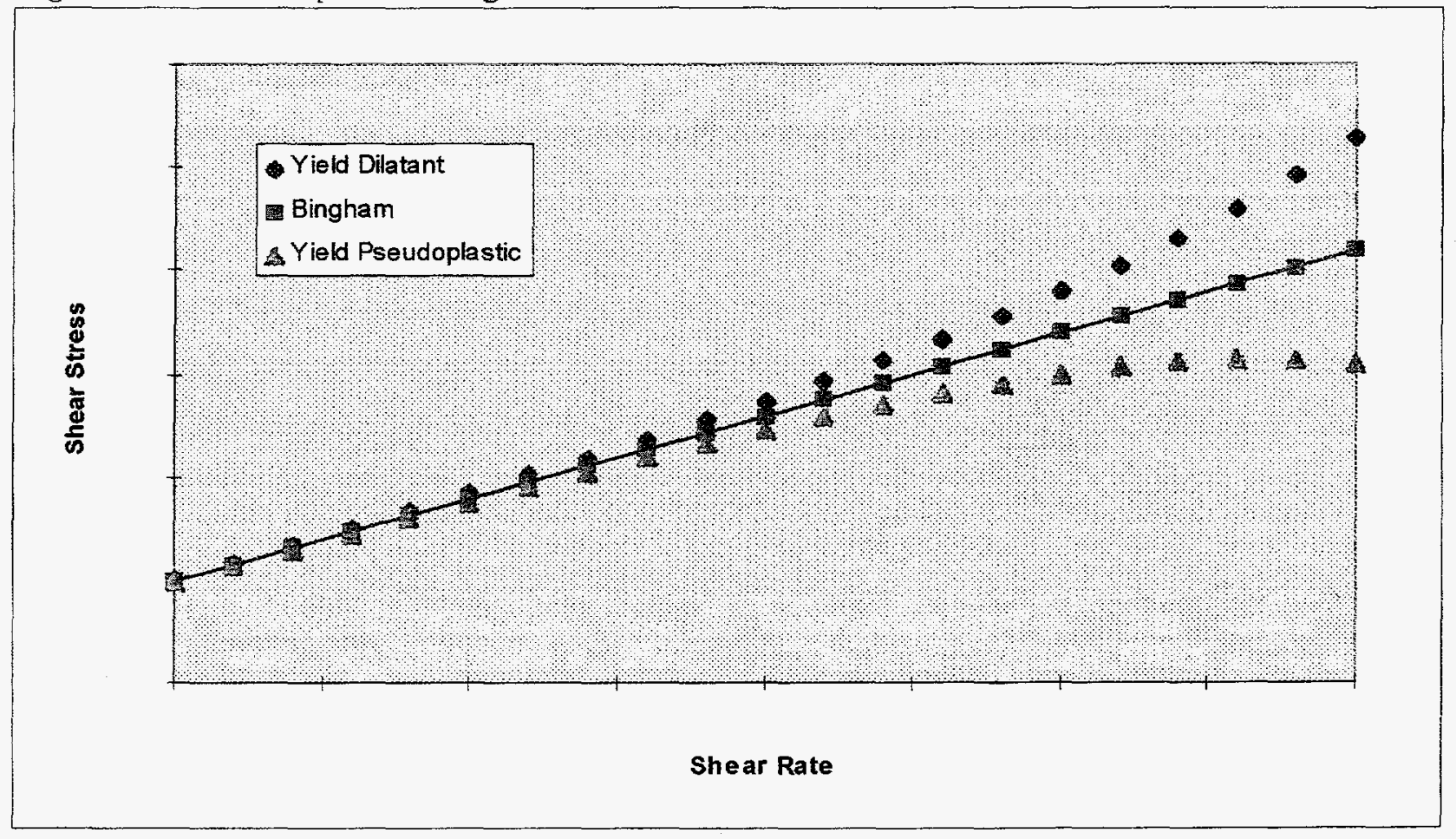


The pseudoplastic behavior shown in Fig. Al falls below the Newtonian curve which indicates that at high shear rates a pseudoplastic fluid "thins out" such that less stress is required to maintain fluid motion. This pseudoplastic behavior is also called "shear-thinning". In contrast, the dilatant fluid exhibits "shear-thickening" behavior. Fluids that become thinner with time when stirred at a constant shear rate are called thixotropic, and fluids that thicken with time are called rheopectic. When dealing with sludge and slurry samples it is common practice to just note thixotropic behavior rather that to describe it in mathematical terms. Reporting the shear stress required to initiate motion in an undisturbed sludge, defined as the shear strength $\left(\tau_{s}\right)$, is usually sufficient for most applications.

In terms of sludge mobilization, an undisturbed sludge initially behaves as a pseudo-solid with a characteristic shear strength $\left(\tau_{\mathrm{s}}\right)$. As the sludge is initially mixed the slurry becomes a thixotropic fluid when the shear strength is exceeded and as the mixing continues the fluid reaches a steady state condition where the slurry behaves as a power law fluid.

Viscosity is defined as the ratio of shear stress to shear rate,

$$
\eta=\frac{\tau}{\dot{\gamma}}
$$

In other words, viscosity is an indication of the stress required to cause a fluid to flow at a given rate. Fluids for which the viscosity is constant for all values of shear rate are defined as Newtonian fluids and as shown in Fig. A1 the shear stress/shear rate curve for Newtonian fluid is a straight line with a slope equal to the viscosity $(\eta)$ and a $y$-intercept of zero. In practice, most sludge or slurry based systems show non-Newtonian fluid behavior and the viscosity varies with the shear rate.

For additional background, a good review on the rheometry of radioactive sludge and slurry samples can be found in a 1987 report $^{l}$ from Pacific Northwest Laboratory (PNL).

${ }^{1}$ W. O. Heath, Development of an In-Situ Method to Define the Rheological properties of Slurries and Sludges Stored in Underground Tanks, PNL-6083 (April 1987). 


\section{INTERNAL DISTRIBUTION}

1. J. F. Alexander

2. J. S. Baldwin

3. E. C. Beahm

4. C. A. Bednarz

5. J. M. Begovich

6. D. A. Bostick

7-8. Central Research Library

9. J. A. Chapman

10. A. G. Croff

11. S. M. DePaoli

12. J. R. DeVore

13. B. Z. Egan

14-16.J. M. Giaquinto

17. T. M. Gilliam

18. T. D. Hylton

19. R. T. Jubin

20-22. J. M. Keller

23. C. M. Kendrick

24. T. E. Kent

25-26. Laboratory Records Department - RC

27. D. D. Lee

28. B. E. Lewis

29. A. J. Lucero

30. J. J. Maddox

31. R. C. Mason

32. A. J. Mattus

33. C. P. McGinnis

34. L. E. McNeese

35-37. A. M. Meeks

38. T. P. Mills

39. T. H. Monk

40. T. W. Morris

41. T. E. Myrick

42. J. H. Platfoot

43. M. L. Poutsma

44. S. M. Robinson

45. S. T. Rudell

46. T. F. Scanlan

47. F. J. Schultz

48. C. B. Scott

49. M. B. Sears

50. R. D. Spence

51. R. C. Stewart
52. J. R. Stokely

53. P. A. Taylor

54. N. A. Teasley, Jr.

55. L. M. Toth

56. J. R. Trabalka

57. S. D. Van Hoesen

58. J. F. Walker, Jr.

59. J. S. Watson

60. T. D. Welch

61. J. H. Wilson 


\section{EXTERNAL DISTRIBUTION}

62-64. Lockheed Martin Hanford, 2440 Stevens Center, P. O. Box 1500, Richland, WA 99352-1505

J. B. Berry

H. Boston

W. T. Thompson

65-66. MACTEC, 189 Lafayette Dr., Suite C, Oak Ridge, Tennessee 37830

Stan Blacker

Ken Redus

67-70. U. S. Department of Energy, 3 Main, Oak Ridge, Tennessee 37830

Sherry Gibson

C. S. Mims

Elizabeth Phillips

Gary Riner

71-73. Waste Isolation Pilot Plant, U. S. Department of Energy, P. O. Box 3090,

Carlsbad, New Mexico 88221

Michael Brown

Amber Clay

John Suermann

74. Office of Scientific \& Technical Information, P. O. Box 62, Oak Ridge, TN 37831 